University of Louisville

ThinkIR: The University of Louisville's Institutional Repository

Electronic Theses and Dissertations

$7-2012$

\title{
Proposal to modify the mixing system for hydrosolution's processing plant.
}

Alan Michael Hanley 1988-

University of Louisville

Follow this and additional works at: https://ir.library.louisville.edu/etd

\section{Recommended Citation}

Hanley, Alan Michael 1988-, "Proposal to modify the mixing system for hydrosolution's processing plant." (2012). Electronic Theses and Dissertations. Paper 571.

https://doi.org/10.18297/etd/571

This Master's Thesis is brought to you for free and open access by ThinkIR: The University of Louisville's Institutional Repository. It has been accepted for inclusion in Electronic Theses and Dissertations by an authorized administrator of ThinkIR: The University of Louisville's Institutional Repository. This title appears here courtesy of the author, who has retained all other copyrights. For more information, please contact thinkir@louisville.edu. 


\title{
PROPOSAL TO MODIFY THE MIXING SYSTEM
} FOR HYDROSOLUTION'S PROCESSING PLANT

\author{
By \\ Alan Michael Hanley \\ B.S., University of Louisville

\begin{abstract}
A Thesis
Submitted to the Faculty of the

University of Louisville

J.B. Speed Scientific School

as Partial Fulfillment of the Requirements

for the Professional Degree
\end{abstract}

\section{MASTER OF ENGINEERING} \\ Department of Chemical Engineering
}

July 9,2012 
PROPOSAL TO MODIFY THE MIXING SYSTEM FOR HYDROSOLUTION'S PROCESSING PLANT

Submitted by:

Alan Michael Hanley

A Thesis Approved on

(Date)

by the Following Reading and Examination Committee:

Gerold Willing, Thesis Director

Dr. William Biles

Dr. Eric Berson 


\section{ACKNOWLEDGEMENTS}

This project was made possible with the assistance from a number of people. The first to note is Dr. Gerold Willing, my thesis advisor who also provided knowledge on plant design and strategy. Another noteworthy professor is Dr. James Watters, who taught both Plant Design classes in the undergraduate curriculum, giving me the basics I needed to prepare this proposal. I would also like to credit the faculty of the chemical

engineering at J.B. Speed School, who provided me with the training in the discipline of engineering.

David Davis and Jennifer Lewis, Co-Owner and employee of HydroSolutions, respectively, for providing information about the company, the facility, and the issues that required attention on which this project is targeted at. Mr. Davis also helped organize the visit to the facility, where I was able to see first hand how the facility ran and where improvements could be made.

Finally, credit is given to Pamela Denton and the other members of the 2012 Masters of Chemical Engineering class. Mrs. Denton assisted me with research and proposal preparation, as well as accompanying me on the trip to the facility to aid in the analysis. The members of the 2012 masters class provided me with ideas and well as helpful notes to fine-tune the idea presented in this proposal. 
TABLE OF CONTENTS

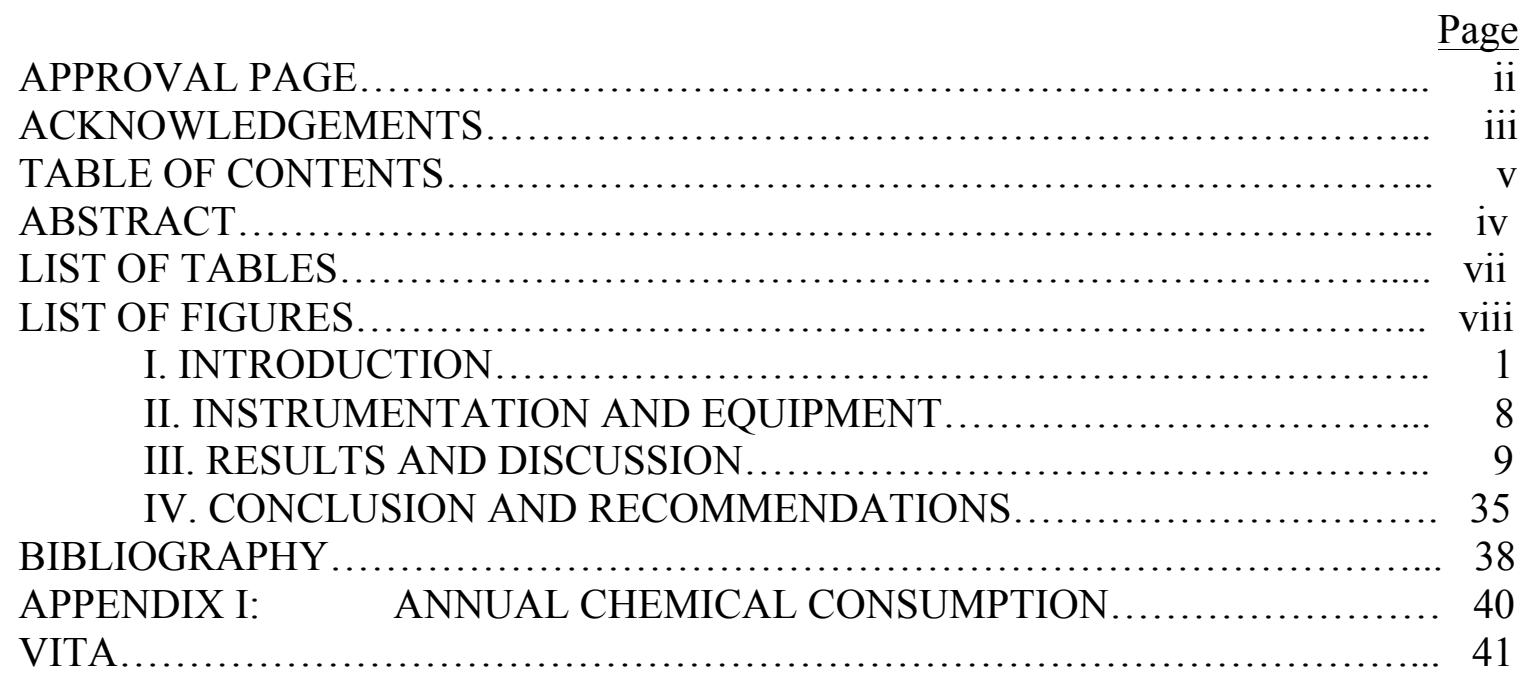




\begin{abstract}
A processing facility in Trenton, Ky owned by HydroSolutions is in need of modernization in order to increase efficiency in the mixing process, improve the safety of the facility, and give the facility the ability to expand in the future. The main idea of HydroSolution's processing strategies is based on a lean manufacturing policy, and as such this zero waste mentality must be maintained after the modifications have been completed. The plant produces a number of chemical combinations that are provided mainly to rendering facilities, as well as other companies in order to remove odors and unwanted chemicals from air streams. For the facility to accomplish the goals listed previously, modifications to existing equipment as well as the addition of new equipment have been recommended.
\end{abstract}

The mixing station within the facility will be refabricated, utilizing semipermanent vessels to hold raw material, as well as involve two larger storage vessels outside for the raw materials that are used more often. Pumps will be installed to load and unload every vessel. The entire mixing system will switch from a gravity driven system using manually operated valves to a pump driven system that utilizes automatic valves. A new software system will be implemented to connect the valves with flow meters in order to mix the product combinations accurately and automatically. The entire 
system will be designed to create the smallest amount of waste possible in order to fulfill the demands of HydroSolutions.

These modifications will greatly improve the efficiency of the facility. A process that would usually be done by two or more operators manually will now be replaced by a process that will be done automatically by one operator. The amount of possible leaks and drip sites on the mixing station has been reduced, increasing the safety and cleanliness within the facility. With these new modifications, the facility will be able to produce more product than ever before, and do so while wasting little to no raw material. 


\section{LIST OF TABLES}

\begin{tabular}{|c|c|c|}
\hline$\#$ & Title & Page \\
\hline I & $\begin{array}{c}\text { Annual Usage of Chemical Substances by HydroSolutions Processing } \\
\text { Facility }\end{array}$ & 11 \\
\hline II & Material Safety Data Sheets for Chemical Substances & 12 \\
\hline III & Cost of Equipment Recommended for Facility & 31 \\
\hline
\end{tabular}




\section{LIST OF FIGURES}

\begin{tabular}{|c|c|c|}
\hline$\#$ & Title & Page \\
\hline 1 & Trenton, KY Current Plant Layout & 3 \\
\hline 2 & Elevated Totes Containing Raw Materials & 4 \\
\hline 3 & Main Union Leading to Exit Valve & 4 \\
\hline 4 & Product Storage Area Located Behind Mixing Area & 5 \\
\hline 5 & Trenton Facility with Proposed Mixing Station Replacement & 10 \\
\hline 6 & New Raw Material Holding Vessels with New Scaffolding System & 13 \\
\hline 7 & Snyder Double Walled HDPE Vessels & 14 \\
\hline 8 & Large Snyder Double Walled Vessel & 16 \\
\hline 9 & Depiction of Outer 10,000 Gal Storage Vessels & 16 \\
\hline 10 & New Mixing System with New Pumps and Piping System & 18 \\
\hline 11 & Pump/Piping System Close-up & 18 \\
\hline 12 & Vessel Loading Inlet & 19 \\
\hline 13 & Innomag Magnetically Driven Pump & 20 \\
\hline 14 & Centrifugal Pump for Non-acidic Compounds & 21 \\
\hline 15 & Koflo Static Mixer with Teflon Fins & 22 \\
\hline 16 & Static Mixer Installed on New Mixing Station Outlet & 22 \\
\hline 17 & Den Hartog 300-gal Low-profile Overflow Vessel & 24 \\
\hline 18 & New Mixing Station with New Ventilation System & 24 \\
\hline 19 & Ventilation Piping System & 25 \\
\hline 20 & Low-profile Overflow Vessel & 25 \\
\hline 21 & New Mixing Station w/ Custom HDPE Containment Boxes & 27 \\
\hline 22 & 2 "3-Way Solenoid Valve with Pneumatic Actuator & 29 \\
\hline 23 & Inline Flow Meter & 29 \\
\hline 24 & Aerial View of the New Trenton Facility Layout & 32 \\
\hline 25 & First View of New Mixing Station & 33 \\
\hline 26 & Second View of New Mixing Station & 34 \\
\hline
\end{tabular}




\section{INTRODUCTION}

The focus of this project involves a processing plant in Trenton, Ky. This facility, owned and operated by HydroSolutions, is used to produce a number of products used to control the odor of airborne emissions from rendering facilities. These products have different combinations of acids, surfactants, as well as other compounds, depending on the specific formula. When this facility was designed, HydroSolutions was producing less than five product mixtures, but today, that number has increased to over twenty different mixtures. With this increase in product combinations comes an increase in both types and quantities of raw materials. While the facility has been modified slightly to allow for these demands, it has become necessary to update the facility to allow for further growth. The purpose of this project is to provide new processing strategies for HydroSolutions by recommending new equipment and modifying/reorganizing existing equipment in the facility in order to increase the efficiency of the process, cut down on the amount of wasted raw materials, increase useable area of the facility, simplify the process for the means of expansion, and make the facility a safer working environment.

HydroSolutions is involved in the control and elimination of odor emissions, as well as the treatment of wastewater and air streams. Established in 1993 and 
based out of Louisville, KY, HydroSolutions began with solving the problems of industrial wastewater treatment. Their service included examination of a specific wastewater stream in order to analyze the key issues for the facility, and then provide a product tailored specifically to that stream to treat the wastewater. Today, HydroSolutions has expanded their specialties to include pollution control and odor elimination for the air streams of animal rendering facilities, again tailoring their products to fit the specific needs of the client company. HydroSolution's products include potable rust inhibitors, odor reactants, and synthetic polymers. (HydroSolutions)

While the exact chemical compositions of HydroSolution's products cannot be disclosed, these products are mainly made of different types and amounts of organic acids and industrial grade surfactants. The purpose of the these products is to induce a chemical reaction inside of a wet air scrubber in order to remove the odor causing compounds from the outgoing air stream. The acids are present in the formula to induce the reaction, while the surfactants are present in order to produce a thorough coating of the product to the packing material. The more thoroughly the packing material is coated, the more contact that the incoming airstream will have with the product. One can expect a maximum level of odor removal if a perfect coating is achieved on the packing. Depending on the nature of the airstream, the organic acids may need to be present in different amounts, concentrations, or possibly removed and replaced with different acids altogether.

The processing facility in Trenton is currently laid out with the mixing area in the middle of the facility, with storage areas set up on the sides. One corner of the 
facility has been walled in in order to create an office and makeshift laboratory. An AutoCAD drawing of the facility is given in Figure 1.

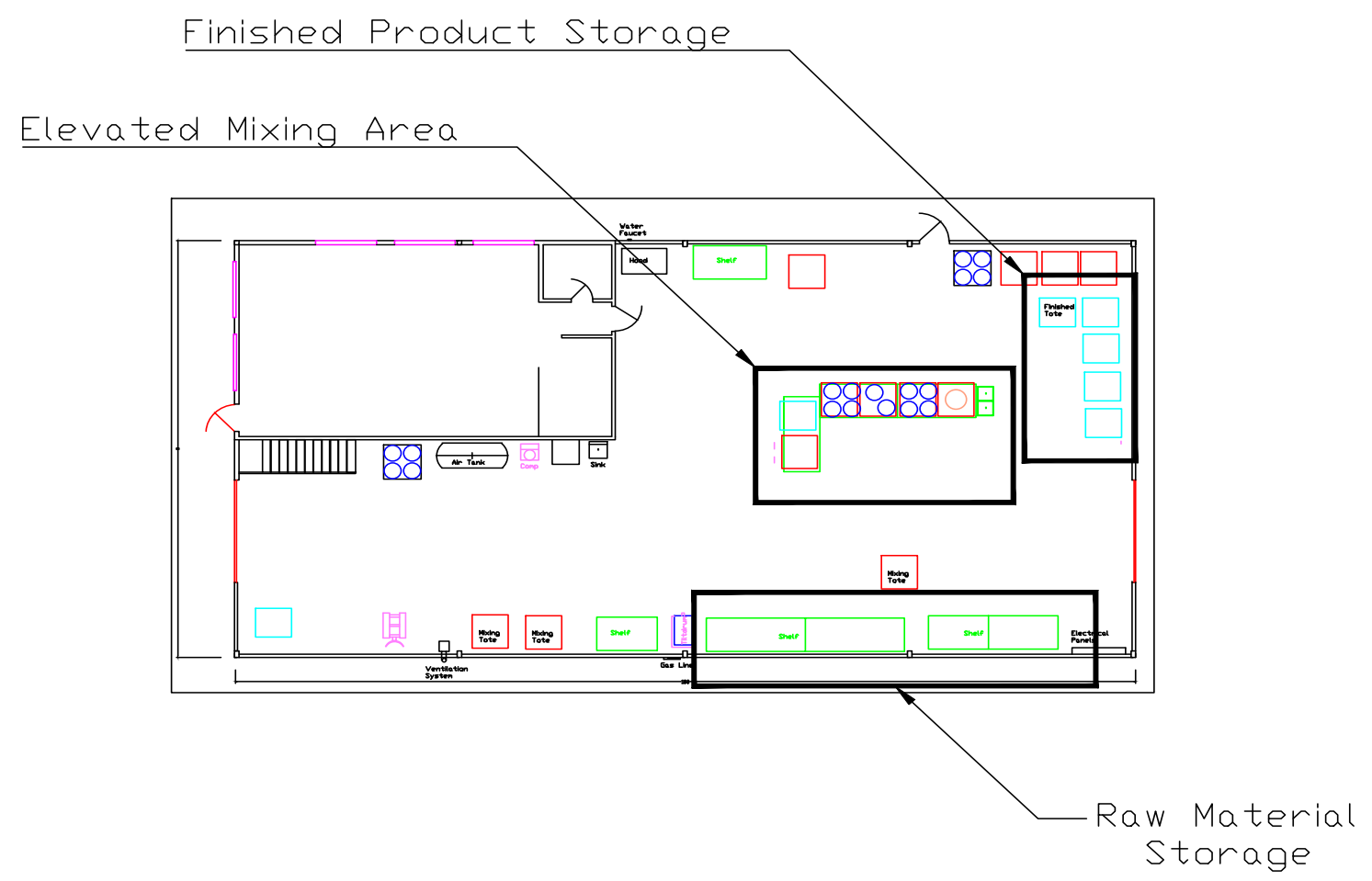

FIGURE 1: Trenton, KY Current Plant Layout

The facility currently uses a gravity driven system in order to fill their totes. The totes of raw materials are loaded onto an elevated platform where they each have individual valve connections. Figure 2 shows how the totes of raw materials are situated. 


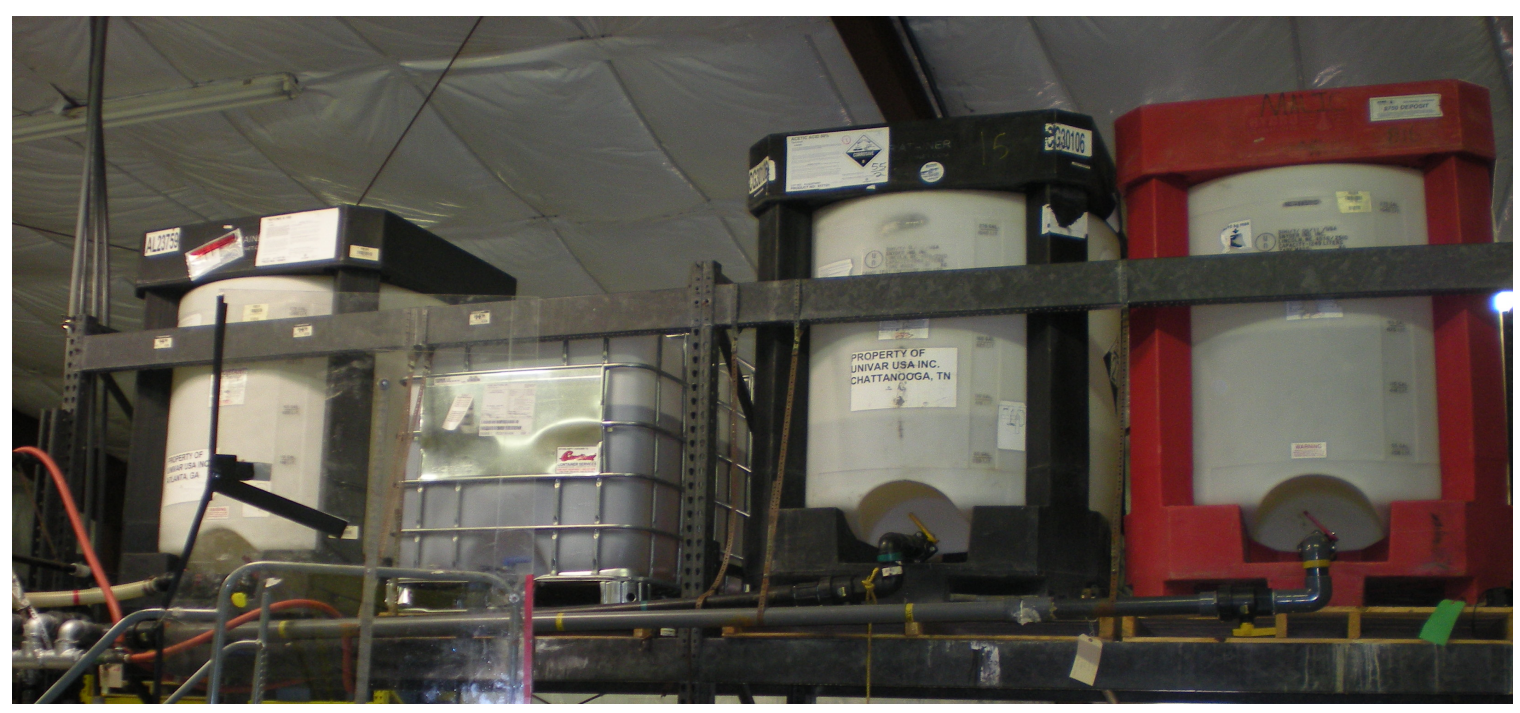

FIGURE 2: Elevated Totes Containing Raw Materials

The totes of raw materials are loaded onto the rack from the backside and are changed out regularly when empty or when a product requires a different combination of materials. The connecting valves to each tote lead to descending pipelines, which lead to one main union with an outlet valve to fill the product tote. A picture of this union is shown in Figure 3.

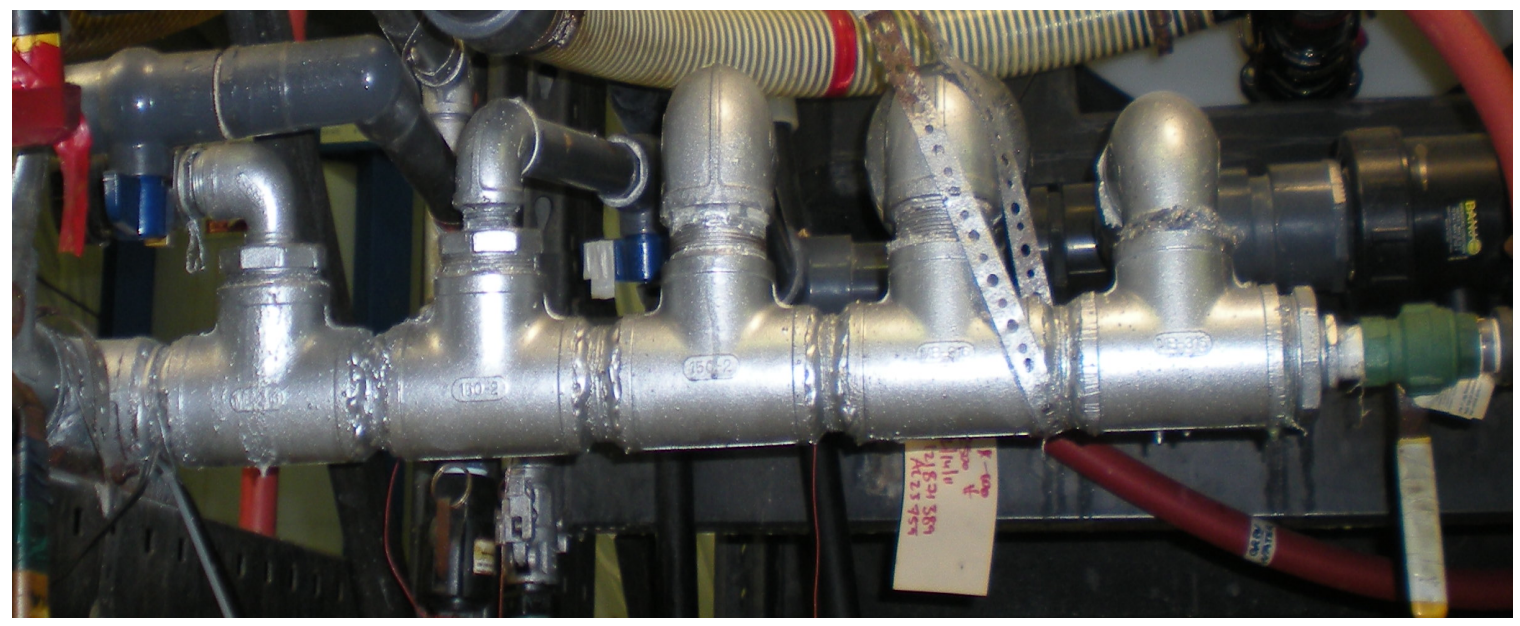

FIGURE 3: Main Union Leading to Exit Valve 
All of the valves used to withdraw the raw materials are operated manually, and the amounts of raw materials for each product mixture are determined by weight of the raw material. Therefore, a scale is placed under the product tote before mixing begins. Once the mixture is completed, the product tote is moved by fork-truck to the storage area of the facility and the system is prepared for the next mixture. The site for product storage can be seen in Figure 4.

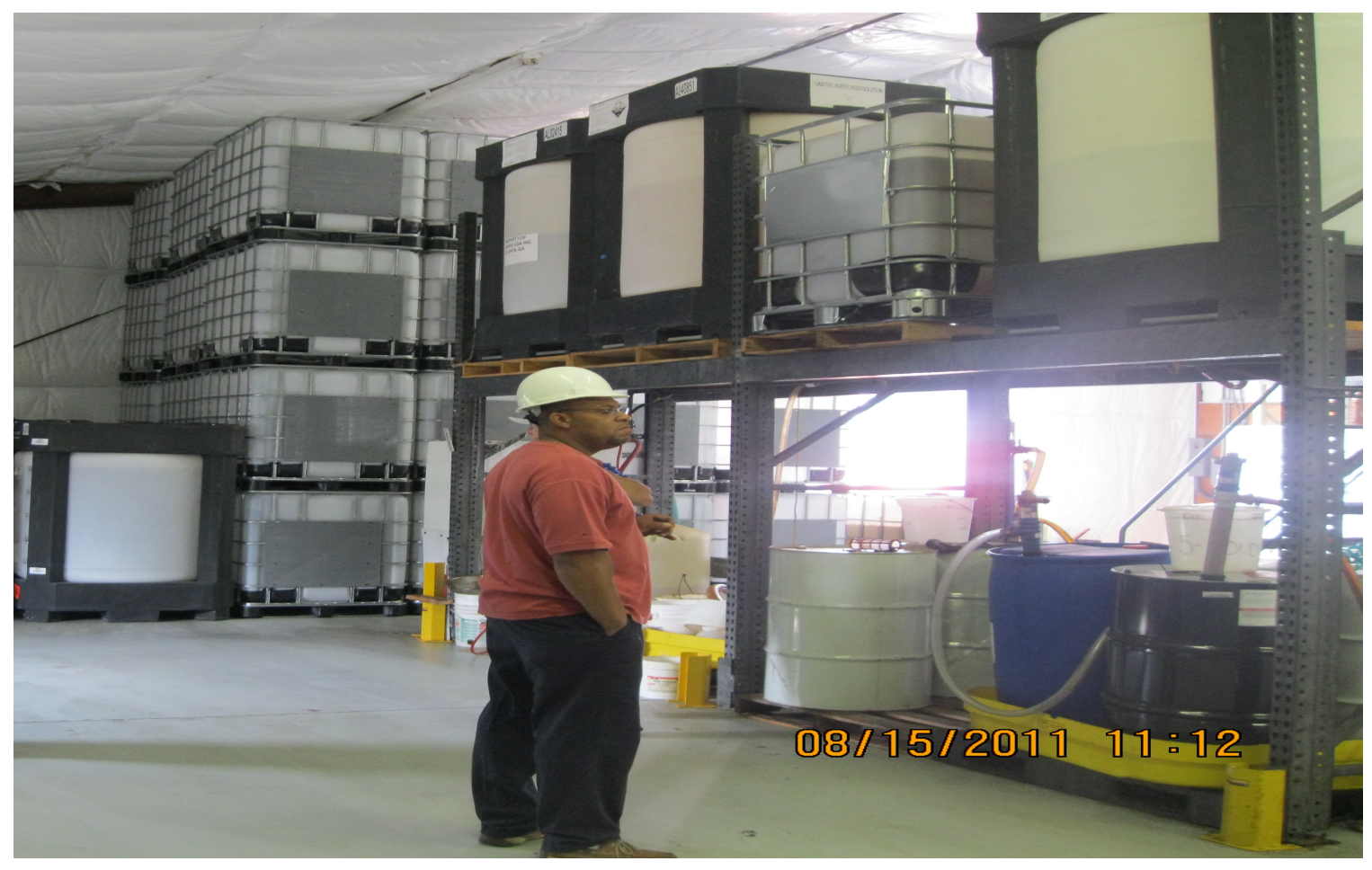

Figure 4: Product Storage Area Located Behind Mixing Area

Due to the increase in both product formulas (which directly relates to the increase in the number of raw materials needed) and the demand for product, the facility has developed a number of problems that have led them to consider renovation and updating. The first issue comes from the design of the mixing 
station. From Figure 2, one can tell that there are only four available slots for totes of raw material, meaning that the operator is forced to wash out and reset the system numerous times throughout the day. If the product requires more than four components, one of the totes will have to be removed by fork truck and the new tote installed by the same means, while the piping connected to that tote will have to be washed with water to avoid unwanted contamination of either the raw material or the product material. This time delay also happens between batches when totes need to be switched out. This limitation on the facility not only causes a massive time delay, but also an amount of waste that the company would like to avoid. HydroSolutions has stressed an importance of employing "lean manufacturing", meaning they would like to have as little waste as possible in their process. Every time a line needs to be washed out, a waste stream is created. Every time a tote needs to be disconnected, there is a chance of wasted raw material, as well as a possible contamination of the facility floor. Eliminating waste in the process was the primary concern of HydroSolutions, making this problem a very high priority.

Another concern for the facility is the lack of proper ventilation for the stored materials. Some of the acids that are used in these mixtures can be hazardous if the fumes are inhaled and/or if the acid becomes gaseous. As of right now, opening both garage doors at opposite ends of the facility can ventilate the building, but this process exposes the air in the facility to atmospheric air. Since the facility is supposed to be temperature controlled, this procedure needs to be replaced with something less disturbing to the facility temperature. While some areas in the 
facility do have systems of ventilation, the main mixing area does not, making this problem another large concern for HydroSolutions.

The last two concerns, while not as crucial but still worthy of attention, are the general layout of this facility and the manual operation of the equipment. As of now, the mixing area is located in the middle of the facility. Possible rearrangement of the mixing and storage areas of the plant could lead to increased usable space. As for the operation of the equipment, the facility would be able to run at a much higher rate, and as such increase their maximum output if they were to adopt automatic control systems. These two concerns will also be assessed in this thesis.

This thesis will present a detailed list of modifications to make to the existing facility. Each modification will include the necessary equipment to achieve the modification, including purchase price and a timeline for installation, as well as a thorough justification of why said modification will benefit the plant. Finally, a comprehensive list of recommendations will be given which will assign a hierarchy of importance for these modifications and suggest both an order of installation and a timeline for the total renovation of the facility. 


\section{II: INSTRUMENTATION AND EQUIPMENT}

Considering the nature of this project, no lab scale equipment was used in the course of the research. The main tool used to develop the results for this project was AutoCAD 2012 Version F.51.M.106. AutoCAD was used to view the building diagrams that were provided for this project, as well as develop the technical drawings of specific process components that are displayed in the Results section of this report. The only other tool used to complete this proposal was a computer with an Internet connection for the purposes of materials research and correspondence with the company. 


\section{III: RESULTS AND DISCUSSION}

After visiting the facility in Trenton, KY and assessing the nature of each individual area of improvement, the following recommendations can be made to improve the efficiency of the facility. The first improvement, dealing with the open area problem that the facility has, is not the most pertinent issue, but provides a basis for the rest of the modifications. The mixing area of the facility will be moved from the center of the facility to the east wall in the northeast corner of the facility to the left of the garage door. Moving the mixing area from the center of the facility to along the wall will not only open up a large area of usable space, but also allow for the other improvements to the mixing system that will be discussed in this section. Currently, the area where the mixing station will be moved to is used for storage of totes containing finished product. Clearing out the middle of the facility will allow for the storage in the southeast corner to be expanded out further from the wall. From the visit to the facility, it became clear that with some organization, the current storage area in the southeast corner could allow for

more storage. After movement of the mixing station and organization of the existing storage area, the southeast corner will have ample space to suit the storage needs for the finished products. An AutoCAD drawing with the proposed modification to the facility is depicted in Figure 5. 


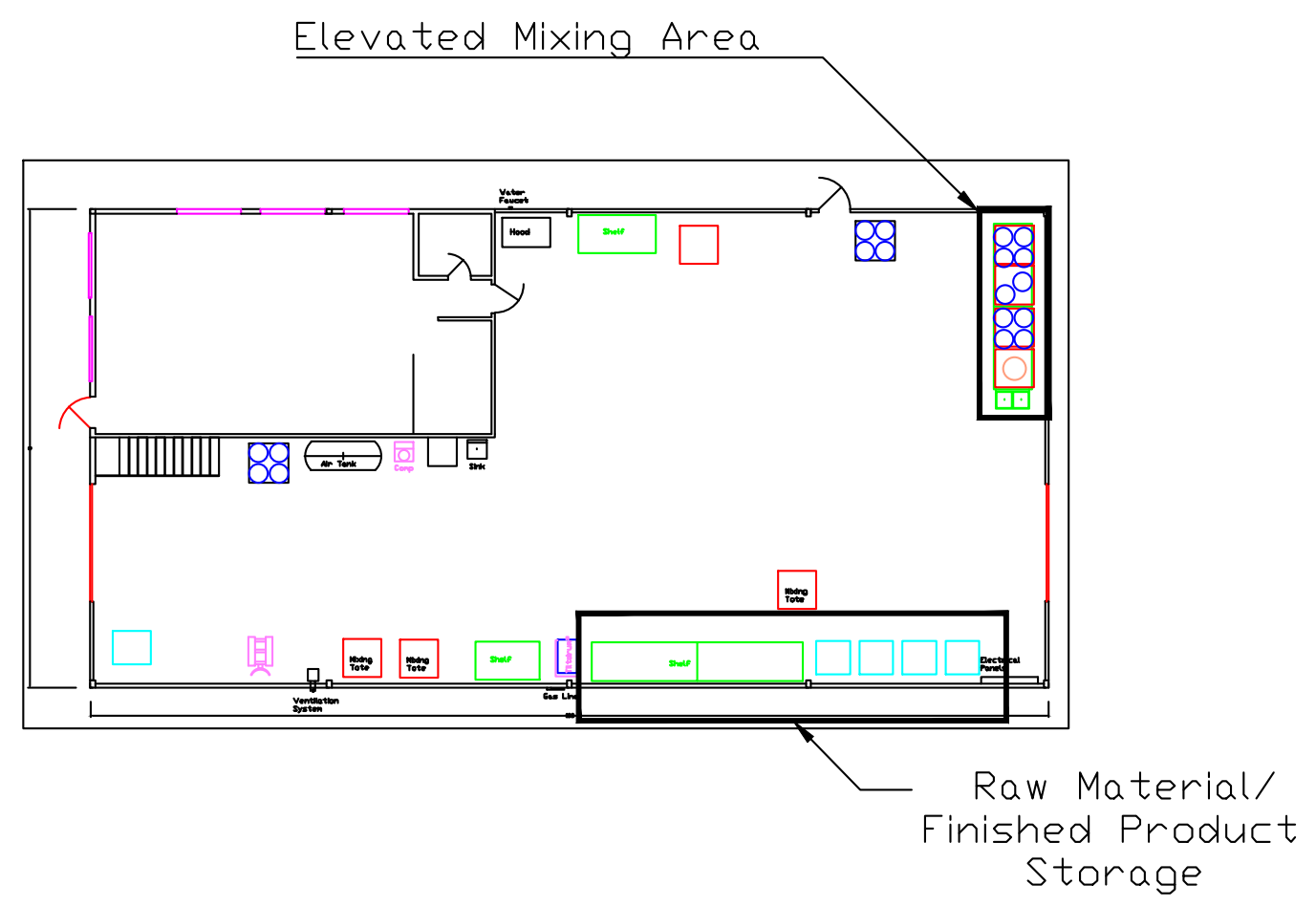

FIGURE 5: Trenton Facility with Proposed Mixing Station Replacement

Now that the mixing station has been moved, the other modifications can be made.

Currently, this facility utilizes eight different chemical compounds on a regular basis in order to prepare their products. A list of these compounds, as well as a rough yearly consumption for each compound is given in Table I. Note, that while the list contains nine entries, malic acid is included twice because of two different methods of acquisition. 
TABLE I: Annual Usage of Chemical Substances by HydroSolutions Processing Facility

\begin{tabular}{|c|c|}
\hline Chemical Substance & Annual Usage (Gallons) \\
\hline Dispersant / Flosperse 3000 & 1438 \\
\hline Acetic Acid (80\%) & 9808 \\
\hline Ferric Acid & 678 \\
\hline Malic Acid (50\%) & 4812 \\
\hline Malic Acid & 927 \\
\hline Sulfuric Acid (78\%) & 4334 \\
\hline BASF T-MAZ 20 & 960 \\
\hline BASF T-MAZ 80 & 160 \\
\hline TX100 & 1977 \\
\hline
\end{tabular}

Now that the number of species and the gallons per year used per species has been established, a new mixing station design can be developed. As previously mentioned, HydroSolutions puts a high price on limiting the number of leaks hazards in their equipment do to the hazardous nature of their raw materials. Complete material safety data sheets (MSDS), which provide National Fire Protection Association (NFPA) ratings, critical temperatures, and other pertinent data regarding these compounds, can be accessed via the links provided in Table II. 
TABLE II: Material Safety Data Sheets for Chemical Substances

\begin{tabular}{|c|c|}
\hline Chemical Substance & Material Safety Data Sheet Links \\
\hline $\begin{array}{c}\text { Dispersant / } \\
\text { Flosperse } 3000\end{array}$ & $\begin{array}{l}\text { http://www.advantagedrillingfluids.com/services/THINNER_III.p } \\
\mathrm{df}\end{array}$ \\
\hline Acetic Acid $(80 \%)$ & http://www.sciencelab.com/msds.php?msdsId=9922769 \\
\hline Ferric Acid & http://www.sciencelab.com/msds.php?msdsId=9925886 \\
\hline Malic Acid (50\%) & http://www.sciencelab.com/msds.php?msdsId=9927566 \\
\hline Sulfuric Acid (78\%) & http://www.ee.iitb.ac.in/ nanoe/msds/sulphuric\%20acid.pdf \\
\hline BASF T-MAZ 20 & $\begin{array}{c}\text { http://worldaccount.basf.com/wa/NAFTA } \sim \text { en_US/Catalog/Chemi } \\
\text { calsNAFTA/pi/BASF/Brand/t_maz/brand_top/ }\end{array}$ \\
\hline BASF T-MAZ 80 & $\begin{array}{c}\text { http://worldaccount.basf.com/wa/NAFTA } \sim \text { en_US/Catalog/Chemi } \\
\text { calsNAFTA/pi/BASF/Brand/t_maz/brand_top/ }\end{array}$ \\
\hline TX100 & http://www.sciencelab.com/msds.php?msdsId=9927635 \\
\hline
\end{tabular}

Because of this emphasis on leak protection, the equipment and strategies used in this design all contain more than one level of leak protection, such as double walled vessels, emergency overfill containment vessels, and custom containment boxes for leak protection. While this equipment is more expensive than the standard versions that could be implemented, it has been determined that these expenses are entirely necessary, and that the price of upgraded equipment is better than the cost of a recordable incident.

The current mixing station is nothing more that metal scaffolding with the piping system bolted onto it. Therefore, scrapping this unit and developing a new one will not be a large expense to HydroSolutions. The new unit will be expanded from seventeen $\mathrm{ft}$. to twenty-six ft., as well as lowered to two $\mathrm{ft}$. off the floor, still supported by a scaffolding system. This will allow the total number of vessels to increase from four to six, as well as cut down on time lost for unhooking and removal of totes. Using pumps to load the product totes instead of gravity, HydroSolutions can lower the entire system, 
removing another dangerous aspect of their current system. Furthermore, the totes will be replaced with semi-permanent vessels, meaning they will not be attached to the scaffolding, but will remain on the scaffolding at all times, only to be removed if the vessel needs to be fixed or replaced.

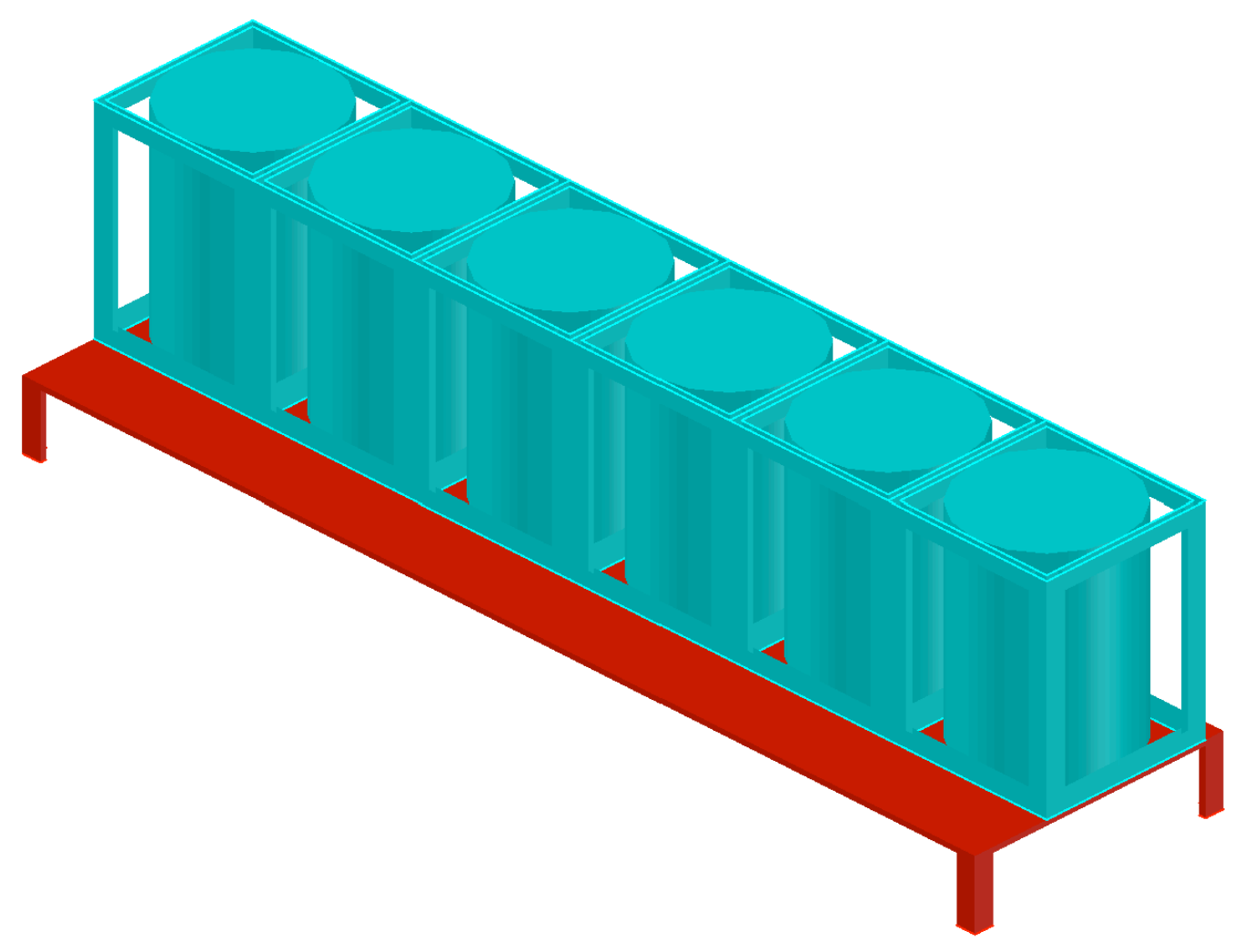

FIGURE 6: New Raw Material Holding Vessels with New Scaffolding System

The vessels chosen for this system are Snyder 500-gal double walled HighDensity Linear Polyethylene (HDLPE) vessels. Each tank has a 53 in. diameter and a 79 in. height. A picture of some of Snyder's doubled walled vessels is depicted in Figure 7. 


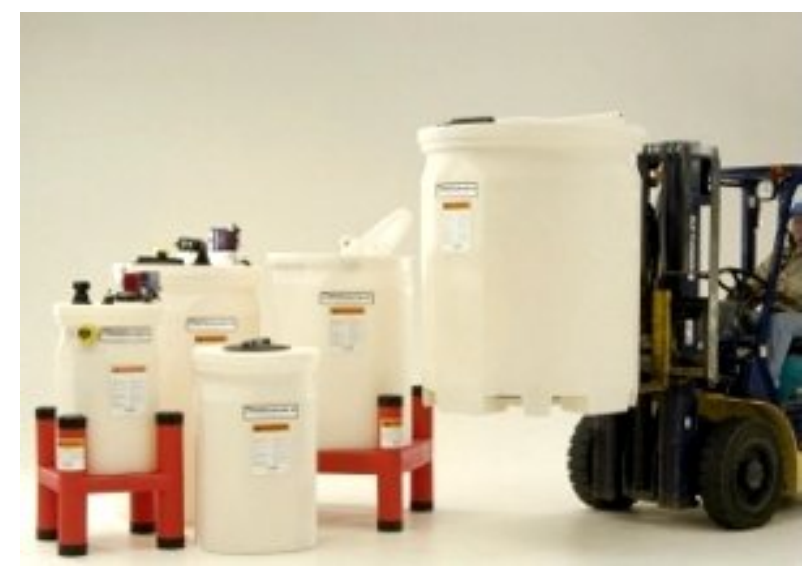

FIGURE 7: Snyder Double Walled HDPE Vessels (www.snydernet.com)

All of the interior vessels will be the same with the exception of the one used to store sulfuric acid. Every chemical with the exception of sulfuric acid has a specific gravity under 1.5, which is what these vessels are rated for. For sulfuric acid, it will be necessary to purchase a vessel rated for a specific gravity of 1.9. The price for these vessels will be roughly $\$ 1780.00$ plus the cost of fittings and shipping. Using double walled vessels will help protect the plant environment from contamination if the inner vessel develops a leak. Using HDLPE for these vessels removes the risk of the acidic raw materials corroding the inside of the vessels. Most importantly, the use of permanent vessels as opposed to a removable tote cuts out the time of replacing empty totes all together. It also removes the task of unhooking the storage containers from the process piping, eliminating a source of waste and a possibly dangerous contamination. These vessels will not only expedite the mixing process, but also make the facility safer for the operators.

The six interior vessels will hold the following chemical compounds, in order from closet to the piping outlet to the furthest: Sulfuric Acid (78\%), Ferric Acid, TX100, Flosperese 3000, BASF T-MAZ 20, BASF T-MAZ 80. This order was chosen to reduce 
the amount of piping that will come in contact with the acids. While the piping materials have been selected to reduce the risk of corrosion, over time the piping will eventually developing pitting. In order to postpone this damage for as long as possible, the acids have been placed as close to the final outlet as possible. The remaining two chemical compounds, Malic Acid and Acetic Acid, will be stored in larger vessels outside of the facility. Do to the quantities of these acids that HydroSolutions goes through annually, larger storage vessels were selected to reduce the number of refills throughout the course of the year. While sulfuric acid is also used in excess, it is necessary to store sulfuric acid of this concentration in a temperature controlled environment do to its high levels of reactivity. To store the remaining two acids, a Snyder 6500-gal double-walled HDLPE vessel has been selected for the Acetic Acid and a Snyder 5500-gal double-walled HDLPE vessel for the Malic Acid. These vessels will be permanently mounted outside of the facility on concrete footers. A picture of a similar Snyder vessel has been given in Figure 8. A depiction of how these vessels will be positioned is shown in Figure 9. Please note that the facility wall will separate the outer vessels from the rest of the system. The scaffolding system has been included in Figure 9 to give an idea of the proximity of the vessels to the rest of the system. 


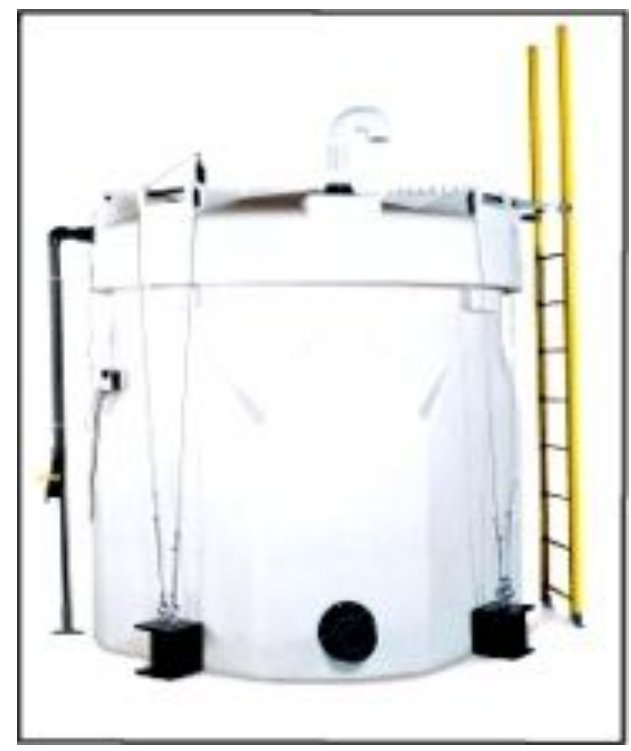

FIGURE 8: Large Snyder Double Walled Vessel (www.snydernet.com)

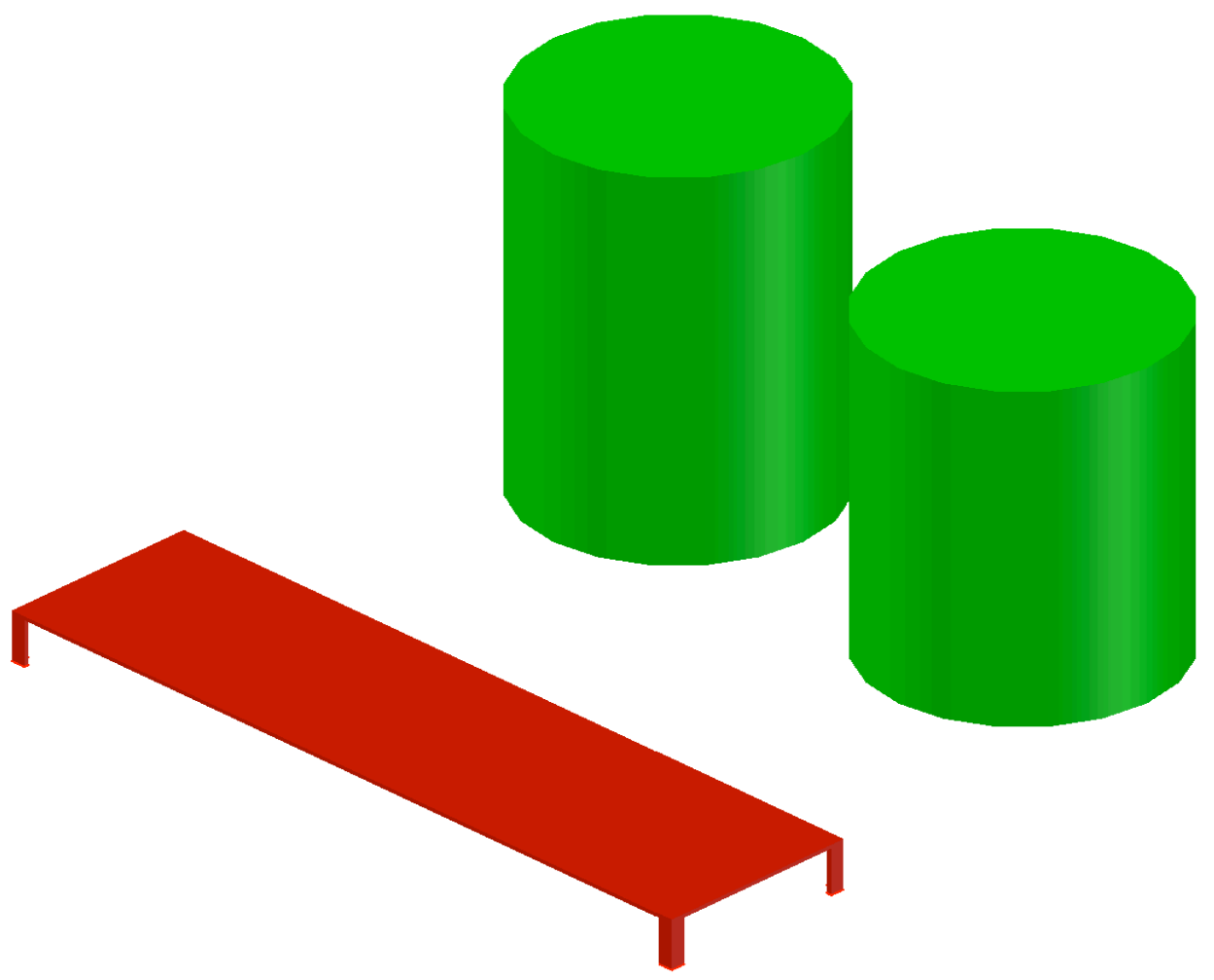

FIGURE 9: Depiction of Outer Storage Vessels 
Installing these larger, outdoor vessels will cut down on the number of refills/resets in the facility, cutting down on the process time and increasing the efficiency of the facility. Also, as it is with the interior vessels, using a permanent structure will cut down on the number of possible leaks and drip sites, which further decreases the amount of wasted raw material. Finally, holding these chemicals outside increases the usable storage space inside of the facility, as well as acts as another logical step toward expansion of the facility. Depending on the rate of growth of the company, it could possibly become necessary to move all raw material storage in larger, outdoor vessels of the size. The 5500-gal vessel will cost roughly $\$ 14,200.00$ plus the cost of fittings and shipping, and the 6500 -gal vessel will cost roughly $\$ 17,600$ plus the cost of fittings and shipping.

In order to load and unload the new vessels, a new pumping system has been added to the mixing station. Using three way valves and a unique piping scheme, these pumps will be able to unload raw material from the delivery totes into the semipermanent vessels, as well as unload from the vessels to the product tote. Each vessel will be outfitted with it's own pump; the use of eight pumps will cut down on wasted material, as well as remove the possibility of contaminating the vessels. Each vessel will have an independent piping system, in that each vessel has it's own loading inlet, it's own pump, and exiting piping that only comes in contact with the other outlets in the last section of the piping system. Figure 10 shows the mixing system with the piping scheme installed, and Figures 11 and 12 show the connection points of the piping scheme and the pump. 


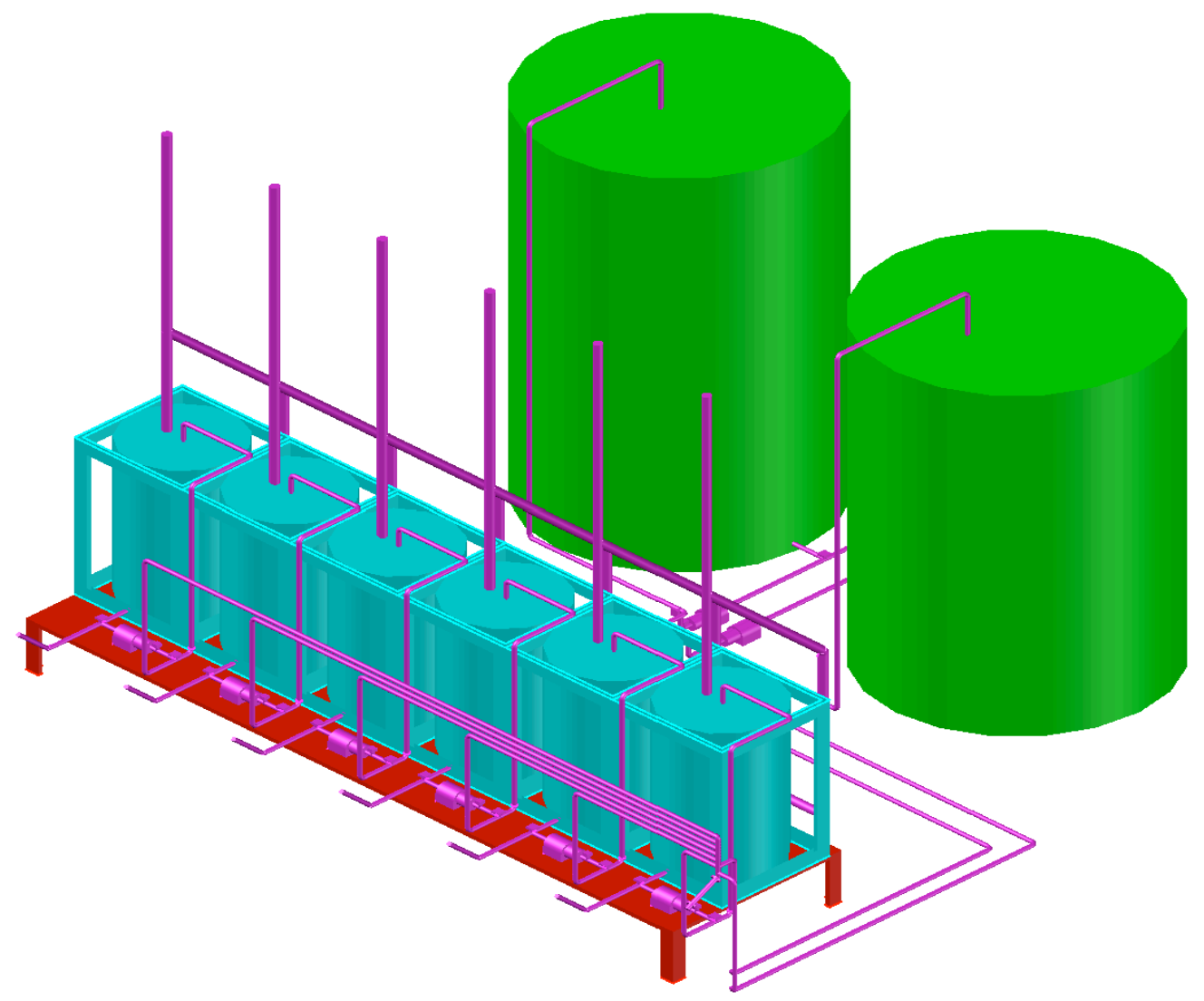

FIGURE 10: New Mixing System with New Pumps and Piping System

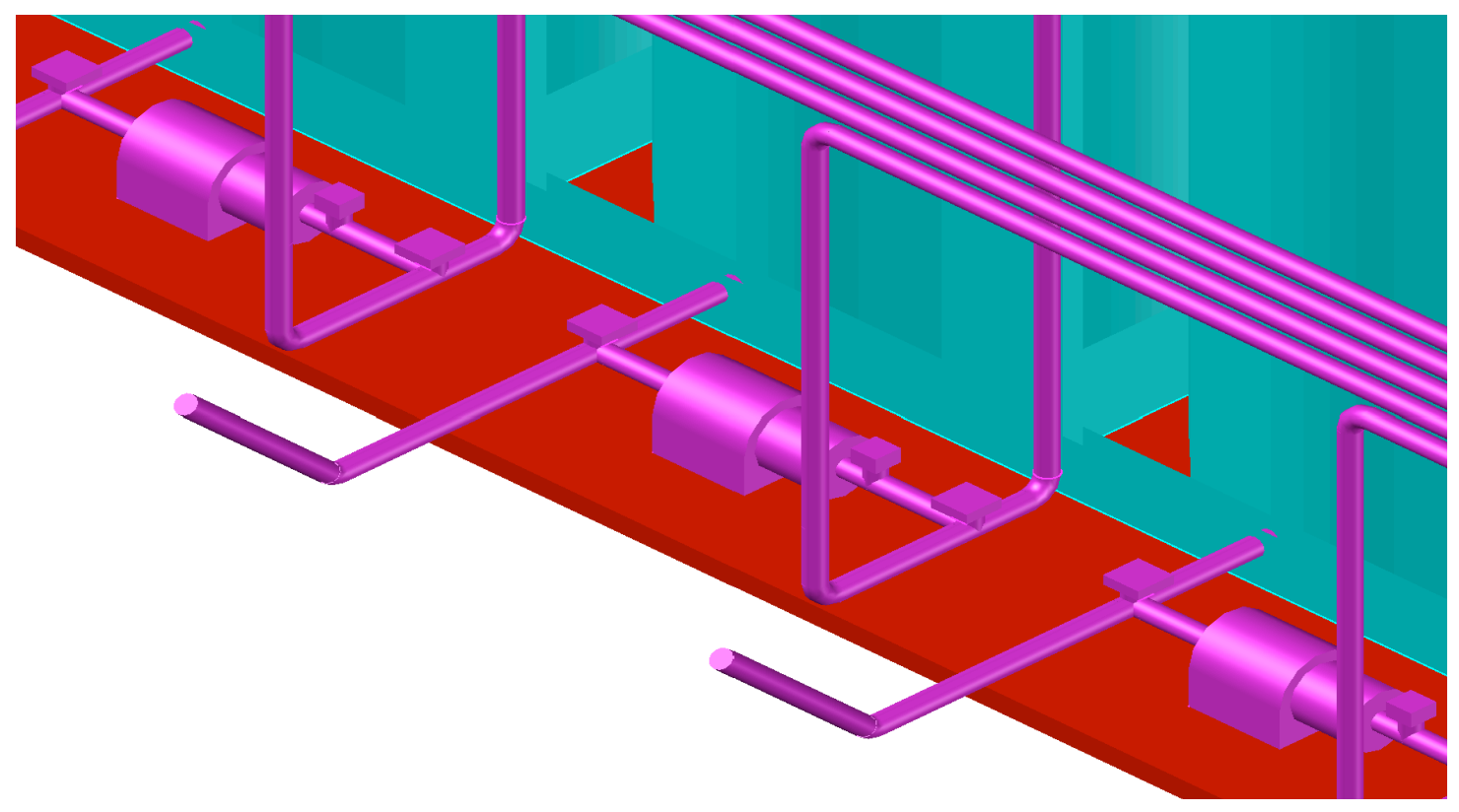

FIGURE 11: Pump/Piping System Close Up 


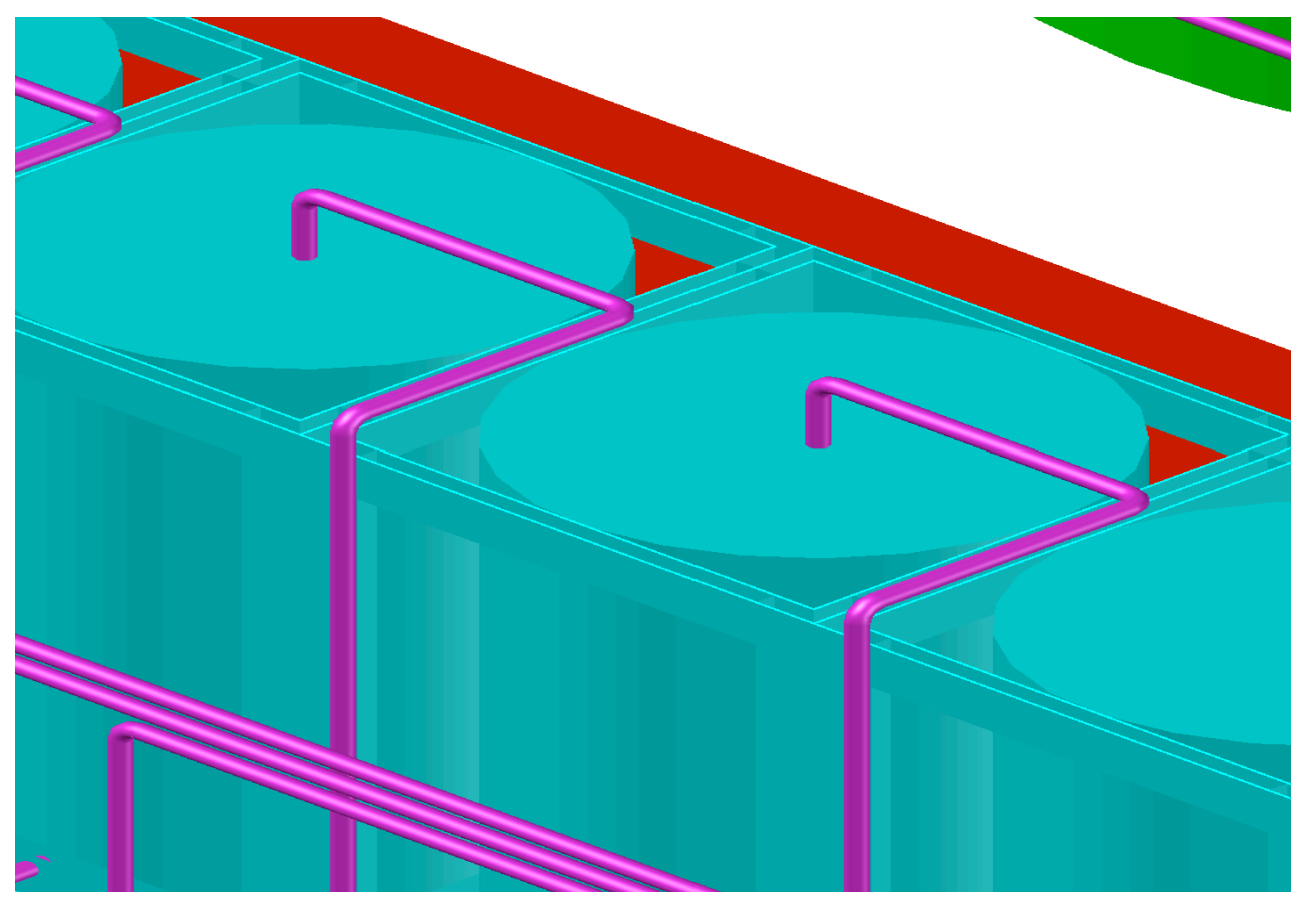

FIGURE 12: Vessel Loading Inlet

For the acidic raw materials, 2" carbon steel piping with a polytetrafluoroethylene (PTFE) coating, commonly referred to as Teflon, will be implemented. The Teflon coating will prevent any corrosion of pitting inside of the piping, while the carbon steel exterior will provide a strong skeleton for the pipe and fittings that will hold up over time. The pump chosen to move the acidic compounds is an Innomag Tefzel ${ }^{\circledR}$ lined magnetically driven pump, capable of achieving 1.2 horsepower (hp) and moving the material at 30 GPM. Tefzel ${ }^{\circledR}$, which is actually ethylene-tetrafluoroethylene (ETFE), is a resin very similar to Teflon, and will act as a suitable lining for the pumps to protect against corrosion. These pumps will also include flow rate control; they will be able to run at full power when loading the materials, but also run at a lower flow rate when product filling operations require less material. The piping/fittings for the section of the 
mixing system that will handle acids will cost anywhere from $\$ 2538$ - $\$ 4778$ per raw material depending on the location of the storage tank. The pumps for the acidic compounds will cost $\$ 5,644$ per pump. A picture of the pump selected is given in Figure 13.

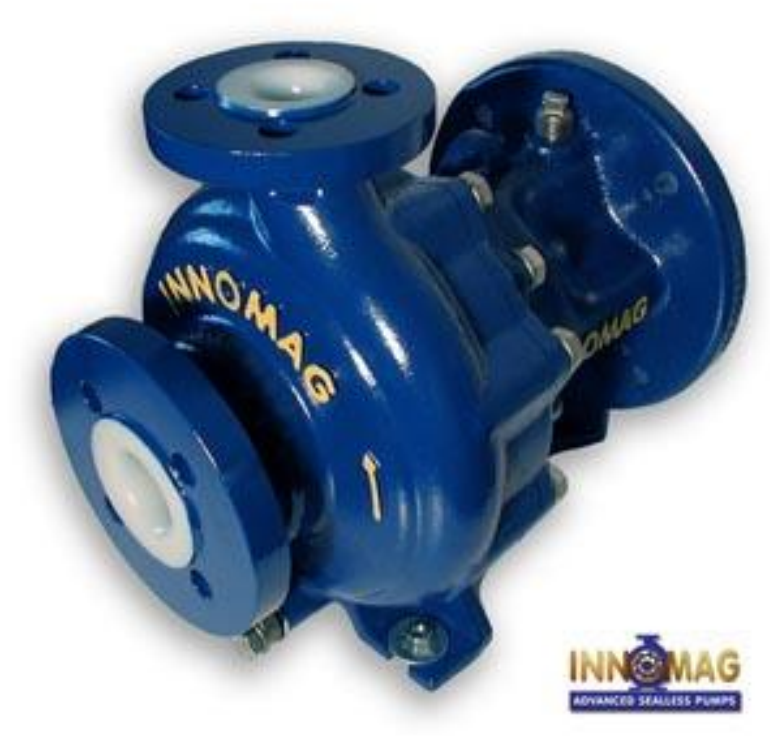

FIGURE 13: Innomag Magnetically Driven Pump (www.innomag.com)

For the non-acidic compounds, a carbon steel piping has been chosen to convey the materials, again sized for 2" diameters for all piping, fittings, and connections. Carbon steel will hold up well over time as opposed to plastic piping or tubing, and with the nature of the non-acidic materials, no internal coating for the piping/fittings is necessary. This section of the mixing station will use centrifugal pumps, capable of achieving 1 horsepower (hp) and moving the material at $30 \mathrm{GPM}$. Like the pumps in the acid section of the mixing station, these pumps will also have the ability to run at a lower flow rate depending on the facility's needs. The piping/fittings for this portion of the 
system will cost anywhere from $\$ 300-450$ per raw material, either increasing or decreasing in cost depending on the location of the vessel. The pumps will cost roughly $\$ 1250$ per pump. A picture of a simliar pump chosen for this section of the system is shown in Figure 14.

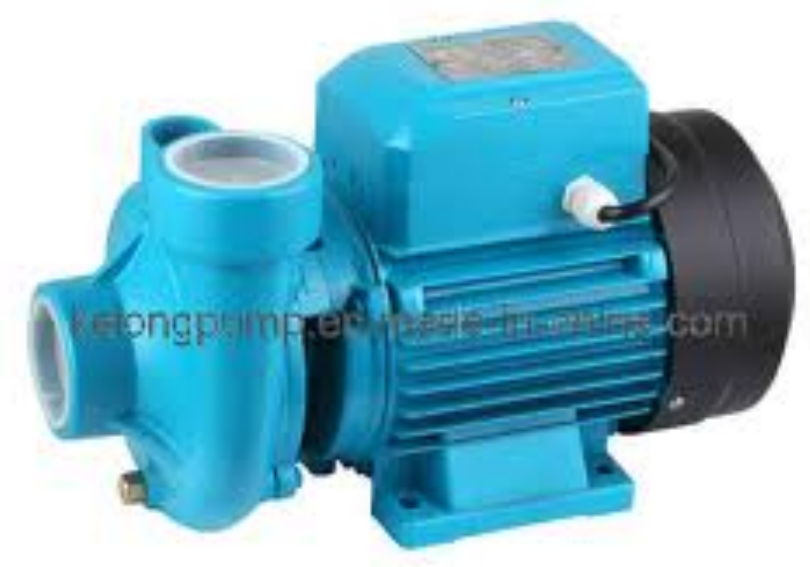

FIGURE 14: Centrifugal Pump for Non-acidic Compounds (kelongpump.en.com)

In order to thoroughly mix the compounds together, the new station will implement a static mixer at the end of the outlet union. Specifically, a 2" carbon steel inline static mixer with a Teflon lining manufactured by Koflo Corporation, which will thoroughly mix the compounds together through the use of Teflon fins installed within the piping. A picture of a static mixer with the fins exposed is given in Figure 15, and a close up view of the mixer installed from the main mixing station drawing is given in Figure 16. 


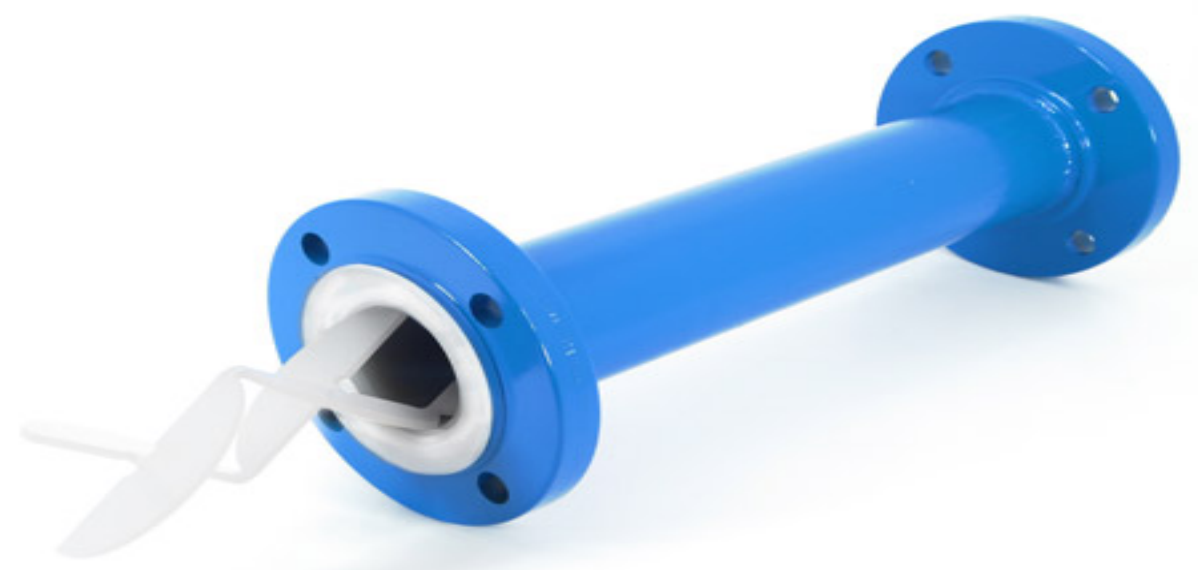

FIGURE 15: Koflo Static Mixer with Teflon Fins (www.koflo.com)

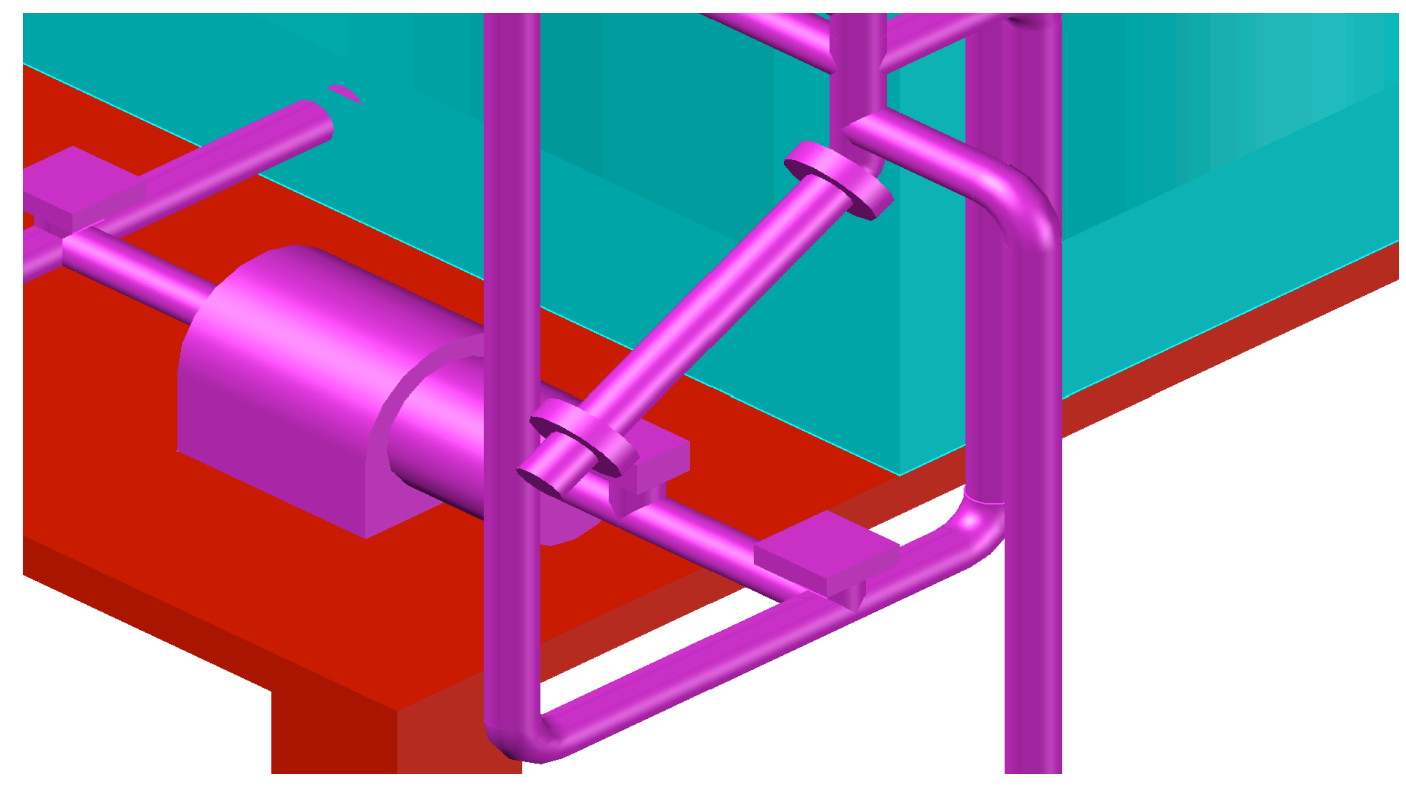

FIGURE 16: Static Mixer Installed on New Mixing Station Outlet

The static mixer will cost $\$ 3,300$ plus the cost of shipping. While this is another substantial cost to add to the project, it is necessary in order to guarantee a thorough mix for the product. 
Another issue that the facility faces is inadequate ventilation for their storage containers. Considering the nature of the chemicals that are used and stored in this facility, it is crucial that each tank be properly ventilated in case any of the acids become gaseous or react. Aside from keeping harmful fumes away from the workers, it is also necessary to vent each vessel in case of any form of a gas build up to relieve the pressure in the vessel. Venting each of these vessels will be accomplished by installing a vertical pipe (either carbon steel or PVC) on each one of the vessels. For the interior storage vessels, the piping will run up and through the roof of the facility, then continued upwards an additional distance to abide by the OSHA regulations for venting tubes. The height of each ventilation tube will depend on the chemical. At the top of each tube, a conical top will be placed above each tube to protect the storage vessel from unwanted contaminants from the outside atmosphere. The outside vessels will be vented in the same fashion. As a further level of protection against unwanted spills, an overflow line has been added to each vent pipe on the interior vessels. These overflow lines will keep and raw material from flowing out of the vent pipe in the instance of an overfilling of the vessel. The overflow lines run down the backside of the system behind the vessels and into a main line where they will flow to an overflow vessel. This vessel will be kept on a pallet underneath the scaffolding for easy removal. While it is possible to run direct piping from this vessel back to the holding vessels, the cost of the extra pump and piping out weighs the convenience. Considering that the facility hopes to never have to use this vessel, the cost of direct piping could not be justified. A special 300-gal HDPE lowprofile vessel manufactured by Den Hartog has been chosen to be the overflow vessel. This vessel cost roughly $\$ 490.00$, plus the cost of shipping and a custom fitting to fit the 
facility's needs. A picture of the overflow vessel is given in Figure 17, and depictions of the mixing station with the ventilation tubes as well as the overflow vessel are given in Figures 18, 19, and 20.

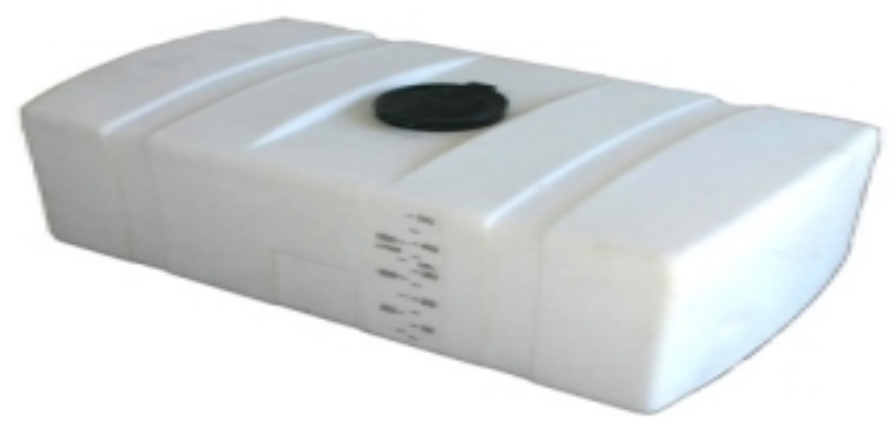

FIGURE 17: Den Hartog 300-gal Low-profile Overflow Vessel (www.usplastic.com)

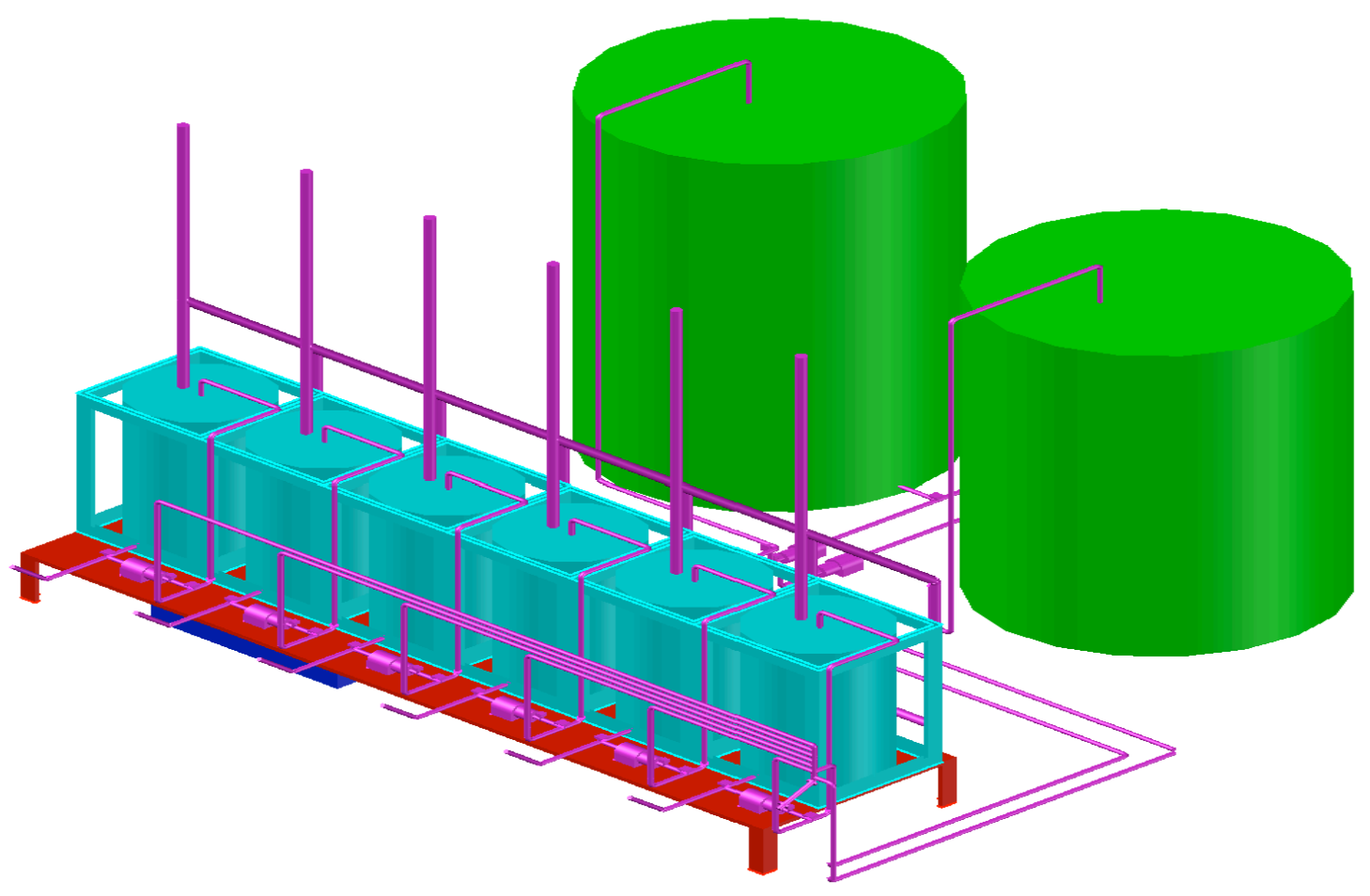

FIGURE 18: New Mixing Station with New Ventilation System 


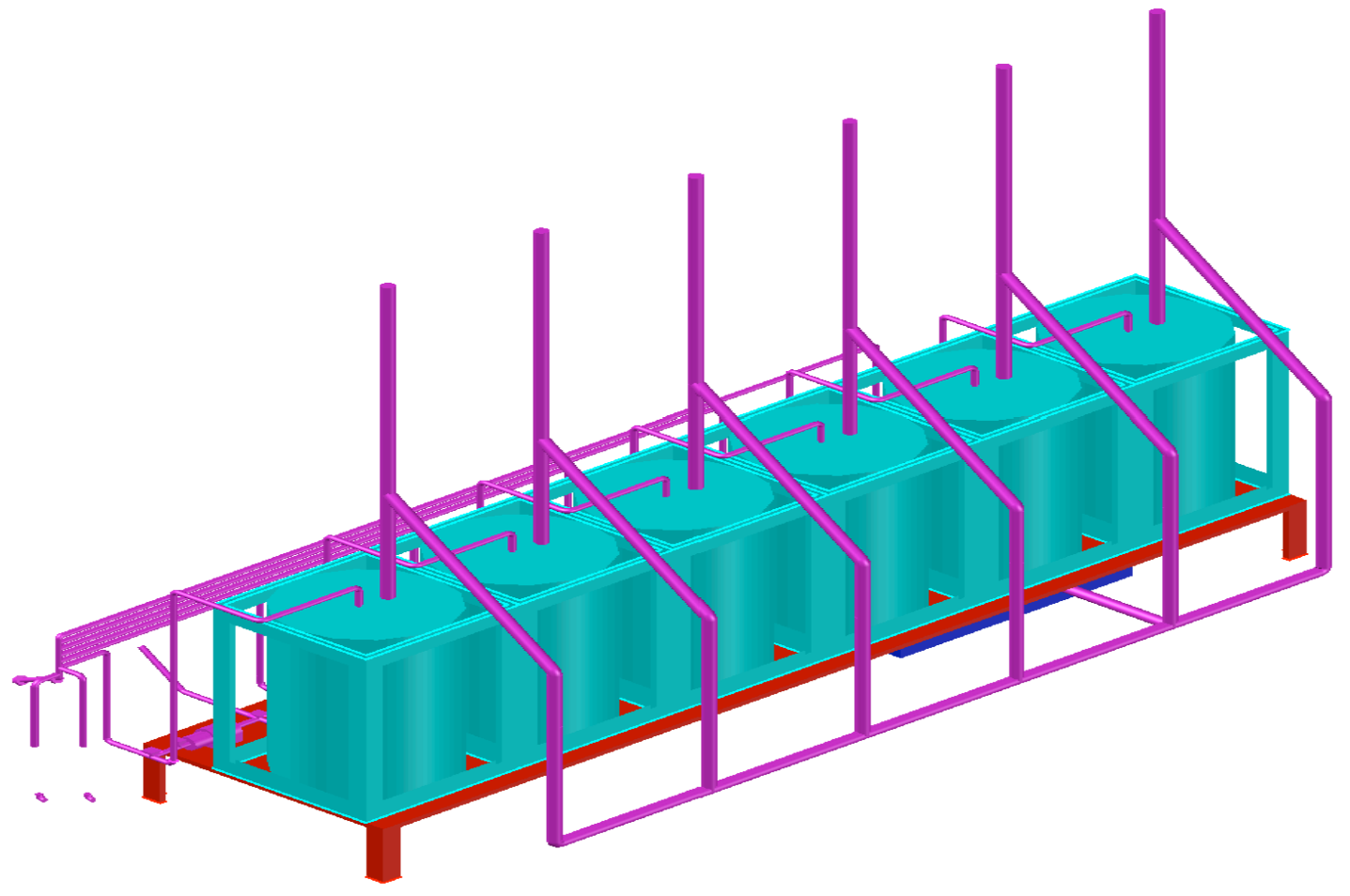

FIGURE 19: Ventilation Piping System

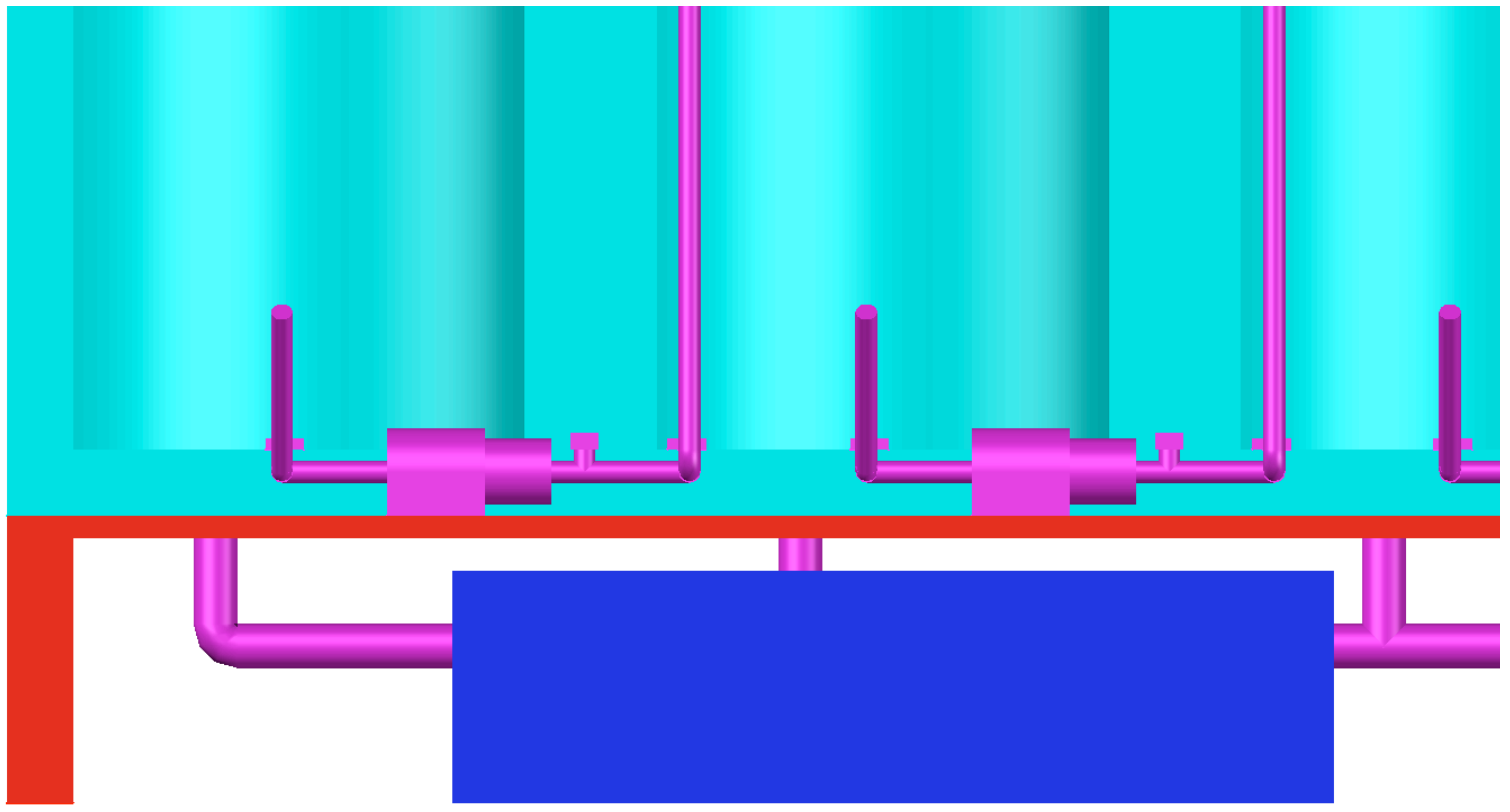

FIGURE 20: Low-profile Overflow Vessel 
Venting all of the vessels in the facility is a relatively inexpensive modification to make; the only cost being the modifications to the roof of the facility and the cost of the piping. This addition to the mixing station is crucial for the sake of general safety as well as equipment safety. It cost less than $\$ 400$ to buy and install a ventilation pipe, but over $\$ 1700$ or more to replace a damaged storage vessel, not including the expenses that come from the loss of raw material and the contamination cleanup for the facility.

As previously stated, containment is a major concern for HydroSolutions when it comes to this facility. Considering the hazardous nature of some of the raw materials involved in this process, it is necessary to have multiple levels on containment. These containment is essential around the pumps, valves, and flow meters, considering these are the most common areas for leaks to occur. Unfortunately, the nature of this system limits the types of containment that can be used effectively. Therefore, custom containment vessels, constructed of HDPE will be added to the mixing station. This containment boxes will be fabricated specifically for the facilities needs, and provide a protective layer around all pumps, valves, and flow meters. Cost for HDPE is relatively low, so this addition will not greatly increase the expense of this project. The containment boxes will also include a hinged top, also made of HDPE, which will remain closed during operation, but will give the operator access for maintenance when the system is not running. A representation of these containment boxes is shown in Figure 21. 


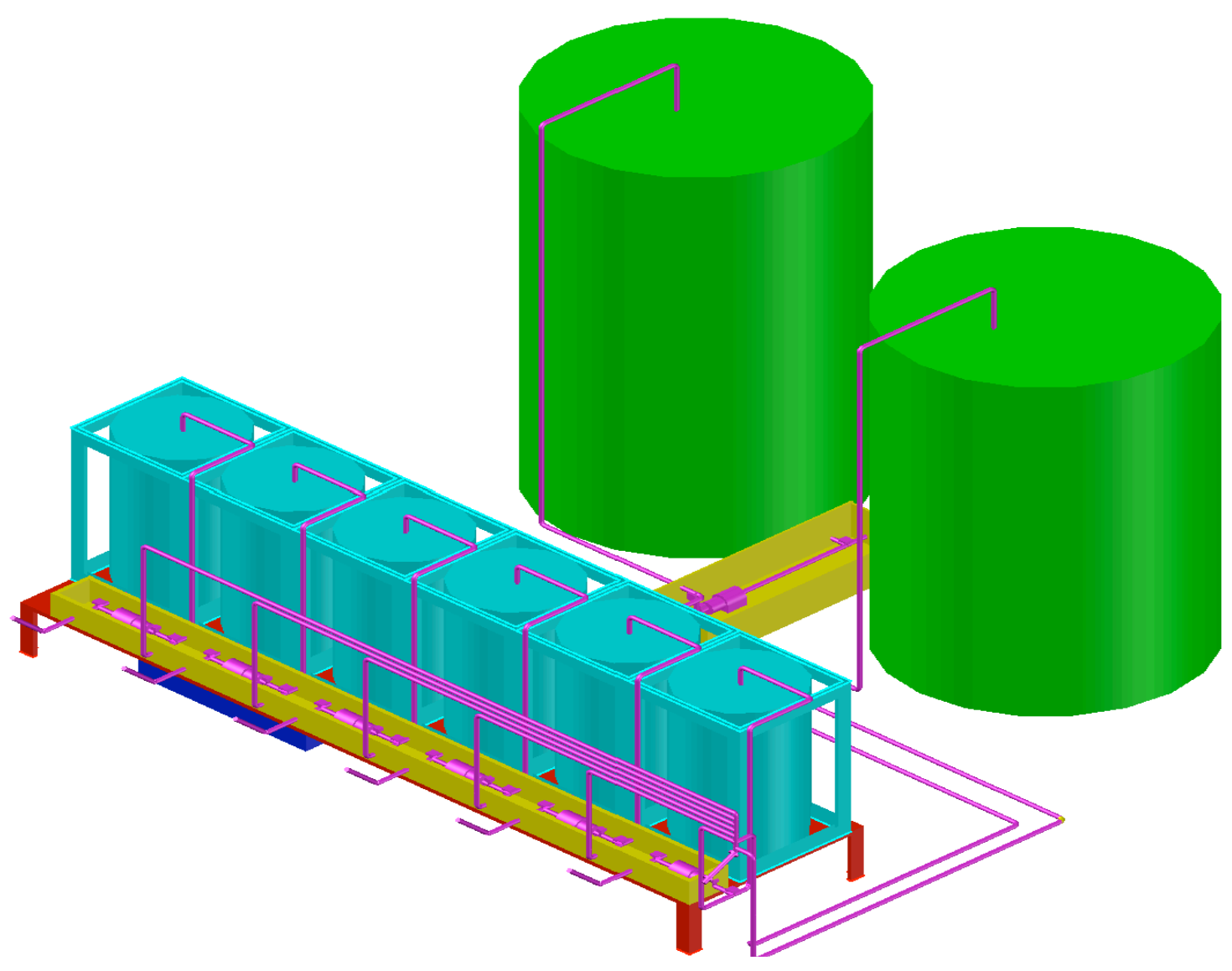

FIGURE 21: New Mixing Station w/ Custom HDPE Containment Boxes

Once the spatial issues and the mechanical issues with this facility have been modified, the final step is modernizing the control system for the mixing station. Be advised that the purpose of this project is to design the mixing system and modify the existing facility. The nature of the controls, as far as software choice, programming, and syncing together all of the automation equipment, will not be discussed in detail in this thesis. While the proper pieces of equipment will be identified, the details regarding the implementation and design of a control system will be handled by either the next engineer to take on this project, or another controls expert all together. 
Currently, the valves on the mixing station are opened by hand and the amount of raw materials per batch is determined by weight. It is recommended that the facility outfit its new mixing station with automatic valves, flow meters, a Programmable Logic Controller (PLC), and a software system to control these components. Of all of the upgrades that have been discussed in this report, this modification gives the largest efficiency upgrade. Essentially, this upgrade will save the facility more time in it process than any other one discussed. The facility will require sixteen 2" 3-way solenoid valves, which include the valve itself as well as an actuator to control the opening/closing mechanism. Partnered with these valves will be eight 2" inline flow meters. The flow meter will constantly calculate the flow going through the pipe and send this information back to the PLC. For the acidic raw materials, the valves and flow meters will be lined with Teflon to prevent corrosion. There are a number of different manufacturers for control software such as the one discussed here (Honeywell is the most well know), and most of the companies that produce the software also will supply or sponsor certain products from partner companies. The software allows the operator to program certain amounts of raw materials to be withdrawn. Therefore, once the proper amount of raw material has been loaded (indicated by the flow meter), the computer will then know to close the valve and stop the pump. Generic photos of these pieces of equipment are displayed in the Figure 22 and 23. 


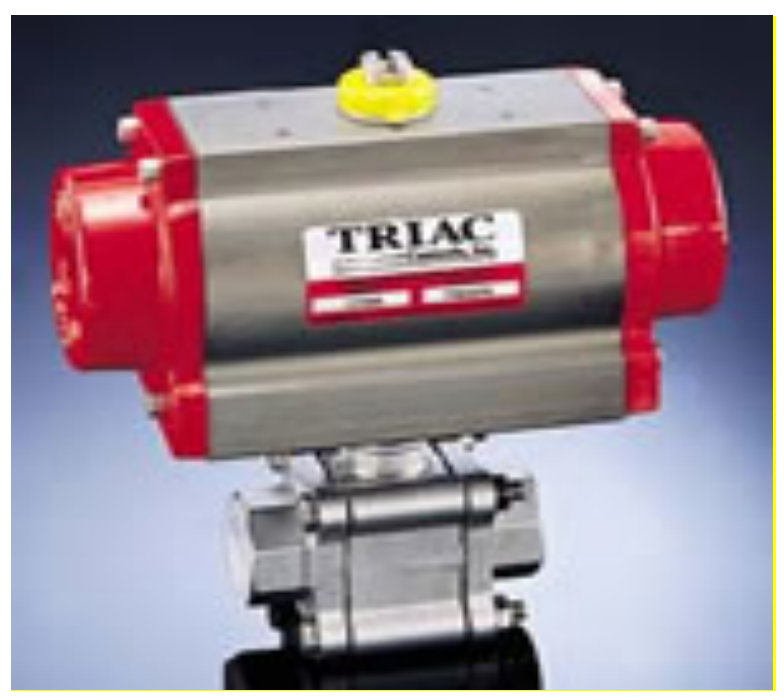

FIGURE 22: 2" 3-Way Solenoid Valve with Pneumatic Actuator (www.thevalveshop.com)

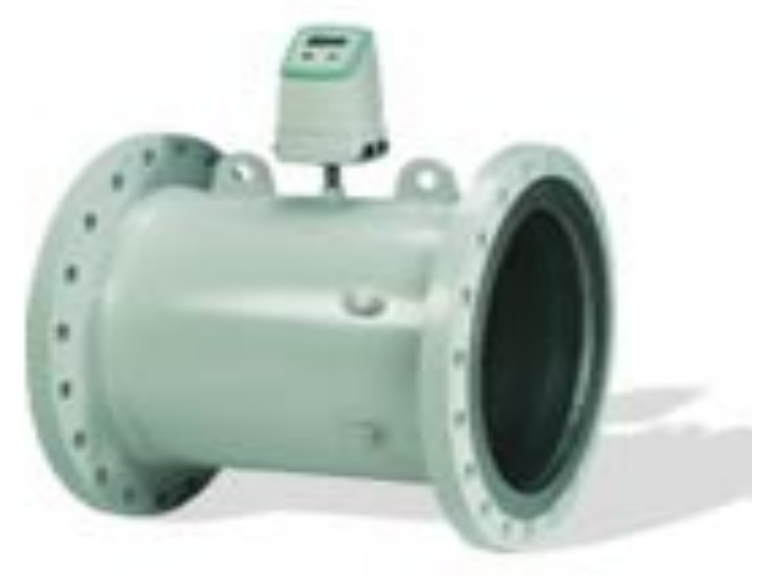

FIGURE 23: Inline Flow Meter (www.rshydro.co.uk)

As stated previously, these modifications to the mixing station will greatly increase the speed at which a tote of product can be produced. With this equipment, the entire process can be done from a computer station, leaving the operator responsible only for watching the monitor for errors and changing out the product totes once the mixture is 
complete. This equipment also ensures accurate results for each tote prepared. Finally, HydroSolutions does have a concern with protecting the exact mixtures in their products since some of the combinations are not yet patented. While operators are required to sign confidentiality agreements, there is always a chance that inside information could leak from the facility. With the mixtures programmed into the software system, an extra level of security is added to the nature of the mixtures. It does not by any standard completely protect the formula, but is an improvement as compared to the current system. Prices for all of this equipment vary depending on the supplier, but have prices that range in the following ways: 2" 3-way solenoid valves without any interior lining range from $\$ 1000$ to $\$ 1500$ each. Unlined valves would be used for the non-acidic compounds. 2" 3-way solenoid valves with a Teflon lining cost roughly $\$ 6875$ per valve, and would be used for the acidic compounds. Flow meters range from $\$ 2000-\$ 4000$ each, the low end being unlined and the high end being Teflon lined.

Table III shows a total cost of all the equipment and materials required to modify this facility. Table III uses the average cost of each component, and does not include the cost of delivery or installation. 
TABLE III: Cost of Equipment Recommended for Facility

\begin{tabular}{|c|c|c|c|}
\hline Equipment & $\begin{array}{c}\text { Number } \\
\text { Required }\end{array}$ & Item Cost (\$) & Total Cost (\$) \\
\hline Overflow Vessel & 1 & 490 & 490 \\
\hline 500 Gal Vessel & 6 & 1780 & 10680 \\
\hline 5500 Gal Vessel & 1 & 14200 & 14200 \\
\hline 6500 Gal Vessel & 1 & 17600 & 17600 \\
\hline $\begin{array}{c}\text { Magnetically Driven } \\
\text { Pumps }\end{array}$ & 4 & 5644 & 22576 \\
\hline Centrifugal Pumps & 4 & 1250 & 5000 \\
\hline Ventilation Piping & ------- & 500 & 500 \\
\hline $\begin{array}{c}\text { Solenoid Valves } \\
\text { (Unlined) }\end{array}$ & 8 & 1250 & 10000 \\
\hline $\begin{array}{c}\text { Solenoid Valves (Teflon } \\
\text { Lined) }\end{array}$ & 8 & 6875 & 55000 \\
\hline $\begin{array}{c}\text { Flow Meters (Teflon } \\
\text { Lined) }\end{array}$ & 4 & 4000 & 16000 \\
\hline Flow Meters (Unlined) & 4 & 2000 & 8000 \\
\hline $\begin{array}{c}\text { Piping (Lined and } \\
\text { Unlined) }\end{array}$ & ------- & -------- & 14800 \\
\hline Static Mixer & 1 & 3300 & 3300 \\
\hline TOTAL & ------ & ----- & $\mathbf{\$ 1 7 8 , 1 4 6}$ \\
\hline
\end{tabular}

Once all of the recommended modifications have been made, the facility will look similar to how it did in Figure 5. Figure 24 shows a layout view of the facility with the listed modifications made. 


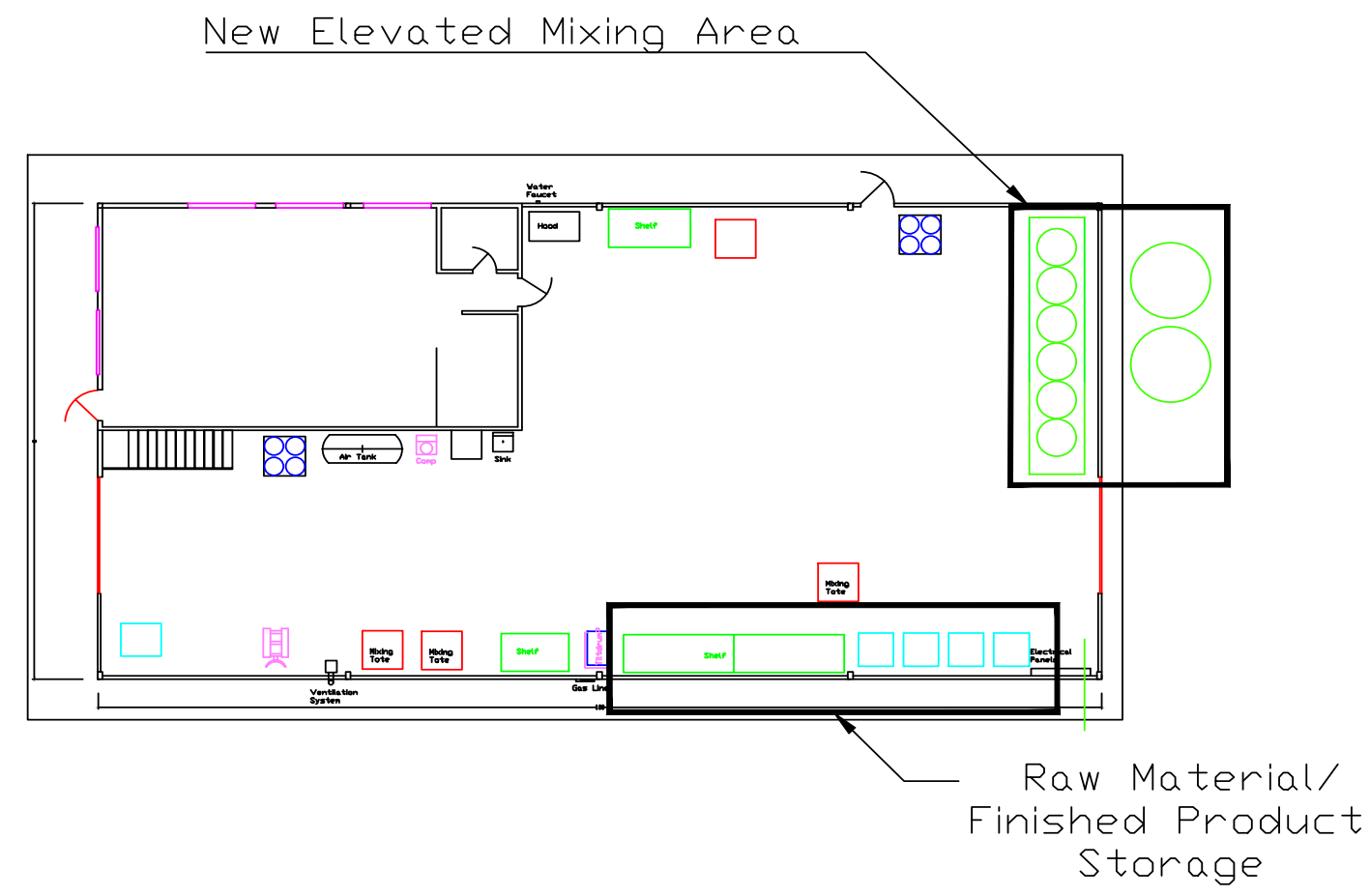

FIGURE 24: Aerial View of the New Trenton Facility Layout

The following figures show the final complete design for the new mixing station for the facility. Multiple views have been provided in order to depict all of the modifications to the original construction clearly. Note that even though it is not depicted in the following drawings, their will be a wall separating the larger vessels from the inside system. The open lines atop each vessel represent the ventilation lines. The lines from the inner vessels will be run through the ceiling of the building and covered with conical roofs to prevent contamination. 


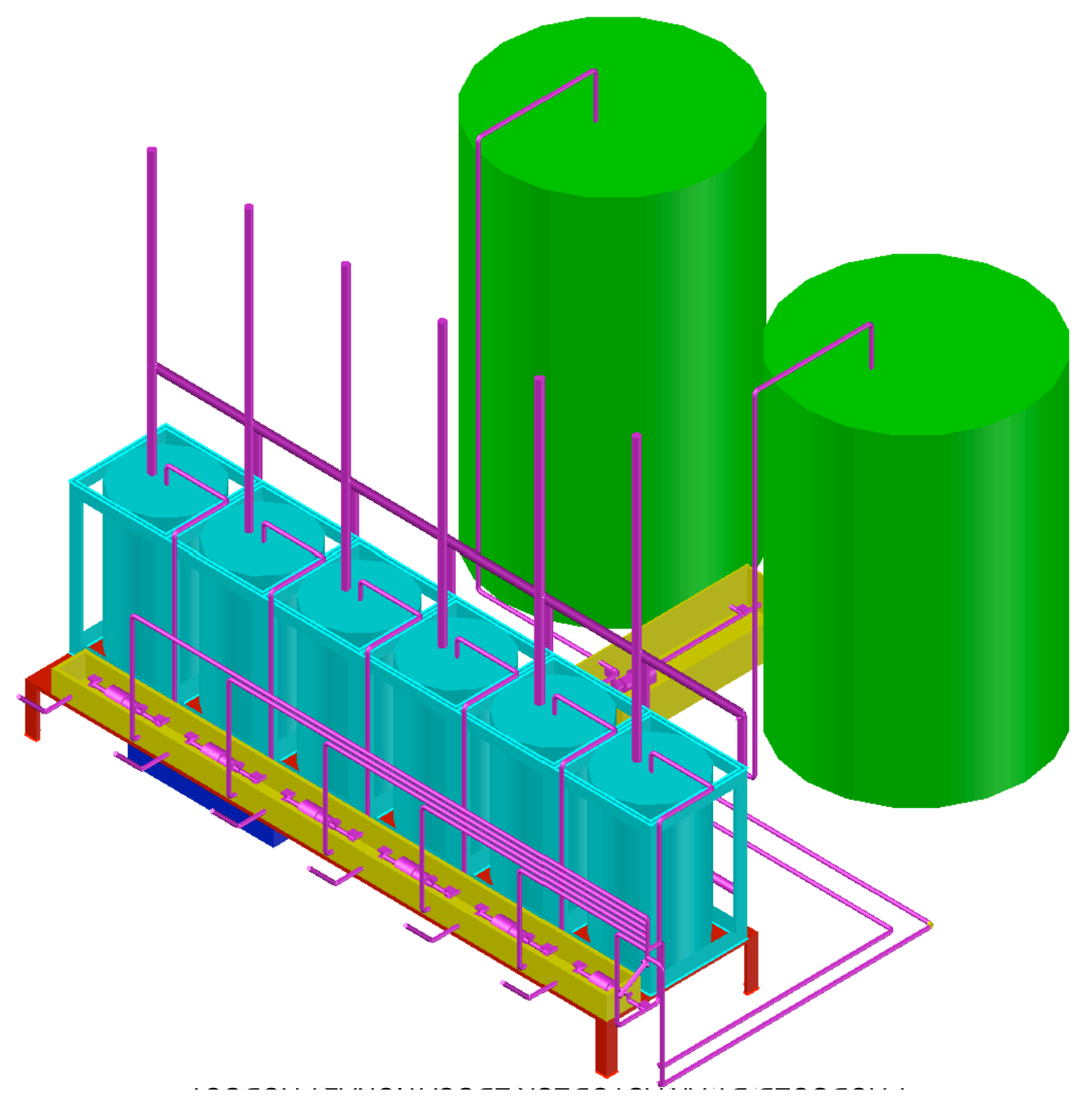

FIGURE 25: First View of New Mixing Station 


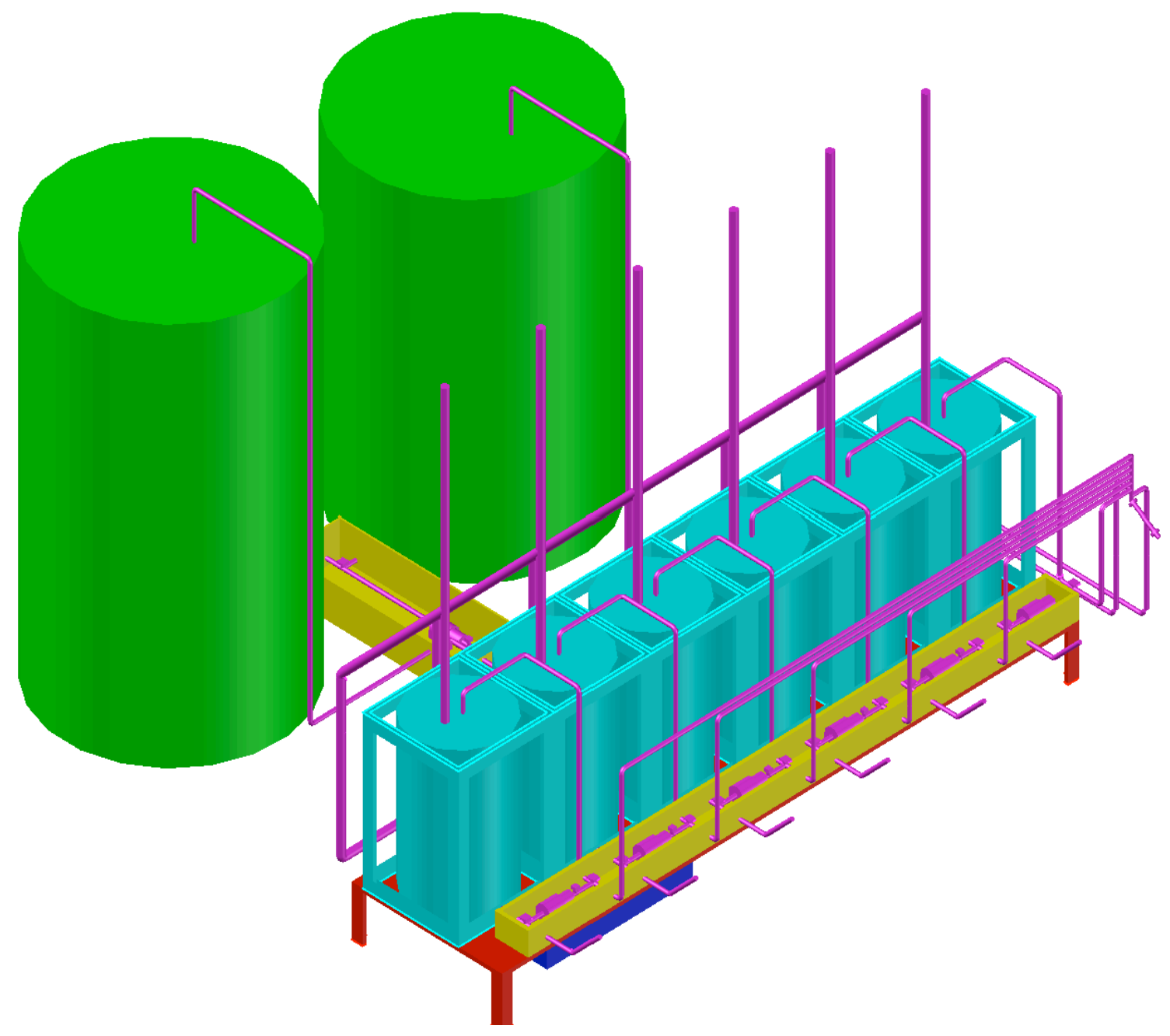

FIGURE 26: Second View of New Mixing Station 


\section{IV: CONCLUSIONS AND RECOMMENDATIONS}

Implementing all of the modifications to this facility will greatly increase the efficiency of their mixing process as well as decrease the amount of waste that the process generates. Having a larger number of raw material's vessels hooked up and ready as well as using larger, permanent vessels will cut out the reset time that the company has had to include in their process. These vessels with their constant connection to the mixing piping will reduce the number of possible raw material leaks, cutting down on wasted material and removing a safety concern for the operators. The ventilation system for each of the vessels will further increase the overall safety standards of the facility. The addition of the new outside vessels will improve the efficiency of the plant, dropping the number of refills for the facility's most popular chemicals to as few as two a year depending on the demand.

The new pump powered loading/unloading system that has been added to the mixing station will not only efficiently fill and unload all of the vessels, but do it in a manner that utilizes almost all of the raw material from the delivery tote. With this design, HydroSolutions can be confident that they are wasting next to none of their materials from the point when they are delivered to when they are shipped out of the 
facility as one of their products. Finally, this entire mixing system has been designed so it can be recreated anywhere in the country, making it much easier for HydroSolutions should they choose to expand to a new facility. This system is limited only by the amount of space that the company can allow it.

The new automation equipment, including the solenoid vales and flow meters, will have the greatest impact on the efficiency of the mixing process. With these additions, the operator will be able to seamlessly switch from producing one product to another, limited only by the time it takes for the product totes to be removed from the mixing station. On top of this, this improvement also makes the operator training for this process very simple, which would make expansion a more simple process for HydroSolutions. Having the combinations of chemicals stored in the computer also gives an extra level of security to HydroSolution's products.

Considering the total expense of this modification and the size of this company, the following recommendations are provided as to the order of purchases and equipment installations. Assuming a worst-case scenario where money is tight, the first purchase should be the pumps for the system. Without the pumps, there is no efficient or easy way to load any of the vessels, so even though they cannot be used immediately, they should be the first expense. After this purchase, $\$ 27576$ has been spent and $15.5 \%$ of the total materials costs have been covered. 
The next step should be purchasing the six 500 gallon vessels, as well as the necessary piping, scaffolding, and ventilation tubes. It will be necessary to purchase additional manual valves to use for the outlet lines from each vessel until later in the project when the automatic valves can be purchased, but considering the low cost of manual valves and the very high cost of automatic valves, this is a necessary expenditure if this system is to be phased in as funds become available. At this point, $\$ 43,366$ has been spent on the project and $24.3 \%$ of the total materials costs have been covered.

The next step would be to purchase and install the larger vessels that would be mounted outside of the facility. Again, manual valves would have to be utilized until the automatic ones could be afforded. After this expense, the company has spent $\$ 75,166$ and $42.2 \%$ of the total materials costs have been covered. Note that the costs of shipping and installation will be much greater in this step of the process, considering the size of the equipment, as well as the materials needed to install these vessels.

The last step is to purchase and install the automatic solenoid valves and the flow meters. This will be the most expensive step of the project. After installation, the plant will be running at maximum efficiency and will have completed the upgrade to the system. 


\section{BIBLIOGRAPHY}

1. Davis, David. 2012. Private Communication

2. Lewis, Jennifer. 2012. Private Communication.

3. No Author. "Acetic Acid MSDS." Material Safety Data Sheet. November 1, 2010. http://www.sciencelab.com/msds.php?msdsId=9922769. April 4, 2012

4. No Author. "Conical Tanks." The Tank Depot. April 4, 2012. http://www.tankdepot.com/productsearch.aspx?search=conical $\& x=10 \& y=19$. April 4, 2012

5. No Author. "Corrosion Fluid Products Corp." Corrosion Fluid Products Corp. 2012. http://www.corrosionfluid.com/June 1, 2012

6. No Author. "DL-Malic Acid MSDS." Material Safety Data Sheet. November 1, 2010. http://www.sciencelab.com/msds.php?msdsId=9927566. April 4, 2012

7. No Author. "Ferric Chloride TS MSDS." Material Safety Data Sheet. November 1, 2010. http://www.sciencelab.com/msds.php?msdsId=9925886. April 4, 2012

8. No Author. "Fixed Installation Inline Ultrasonic Flowmeter." Rshydro. 2012. http://www.rshydro.co.uk/Fixed-Installation-Ultrasonic-Flowmeters-c-394.html. April 4, 2012

9. No Author. "Flow Meters \& Control Valves." Raven. 2009. http://www.sprayers.com/2011/133-137.pdf. April 4, 2012

10. No Author. "HydroSolutions." HydroSolutions. 2011. http://hydrosolutions.com/. April 4, 2012.

11. No Author. "Industrial - Double Wall Containment Tanks." Snyder Industries, Inc. http://www.snydernet.com/industrial_tank_line_captor.htm June 1, 2012 
12. No Author. "Innomag TB-Mag Series." Innomag: Advanced Sealless Pumps. 2011. http://www.innomag.com/index.php/products/tb-mag-thrust-balancedseries/overview June 1, 2012

13. No Author. "Koflo PFA Teflon Static Mixer." Koflo Corporation. 2011. http://www.koflo.com/static-mixers/pfa-teflon-static-mixers.html. June 1, 2012

14. No Author. "Low Profile Rectangular Tanks." U.S. Plastic Corp. 2012. http://www.usplastic.com/catalog/item.aspx?itemid=25304\&catid=819 June 1, 2012

15. No Author. "Material Safety Data Sheet." Thinner III. June 2, 2006. http://www.advantagedrillingfluids.com/services/THINNER_III.pdf. April 4, 2012

16. No Author. "Pedrollo PluriJet Multi-Stage Self-Priming Centrifugal Pump." AquaScience. 2012. http://www.aquascience.net/jet-pumps/index.cfm?id=438. April 4, 2012

17. No Author. "Pipe Fittings." McMaster-Carr. 2012. http://www.mcmaster.com/\#pipe-fittings/=gynhjj. April 4, 2012

18. No Author. "Sulfuric Acid MSDS." Material Safety Data Sheet. November 1, 2010. http://www.ee.iitb.ac.in/ nanoe/msds/sulphuric\%20acid.pdf. April 4, 2012

19. No Author. "T-Maz Esters." BASF. 2012.

http://worldaccount.basf.com/wa/NAFTA en_US/Catalog/ChemicalsNAFTA/pi/ BASF/Brand/t maz/brand top/. April 4, $201 \overline{2}$

20. No Author. "The Home Depot." The Home Depot. 2012. http://www.homedepot.com/. April 4, 2012

21. No Author. "Triac Series V8 V-Port Control Valve Package." The Valve Shop. 2010. http://www.thevalveshop.com/menu/auto/triaca/triaccv/v8pda.html. April 4,2012

22. No Author. "Triton X-100 MSDS." Material Safety Data Sheet. November 1, 2010. http://www.sciencelab.com/msds.php?msdsId=9927635. April 4, 2012

23. Piper, Pat. “2x2 Vert Inline Cent Pump.” CADForum. March 31, 2012. http://www.cadforum.cz/catalog_en/block.asp?blk=8617. April 4, 2012

24. Willing, Gerold. 2012. Private Communication 


\section{APPENDIX I: ANNUAL CHEMICAL CONSUMPTION}

\section{HYDROSOLUTIONS}

\section{Purchases by Item Summary}

January through

December 2011

\begin{tabular}{lccccc} 
& Jan - Mar & Apr - Jun & Jul - Sep & Oct - Dec & \\
& 11 & 11 & 11 & 11 & TOTAL \\
\cline { 2 - 6 } \begin{tabular}{c} 
Spec Gravity or $\begin{array}{c}11 \\
\text { Density }\end{array}$ \\
\cline { 2 - 6 }
\end{tabular} Pounds & Pounds & Pounds & Pounds & Pounds \\
\cline { 2 - 6 }
\end{tabular}

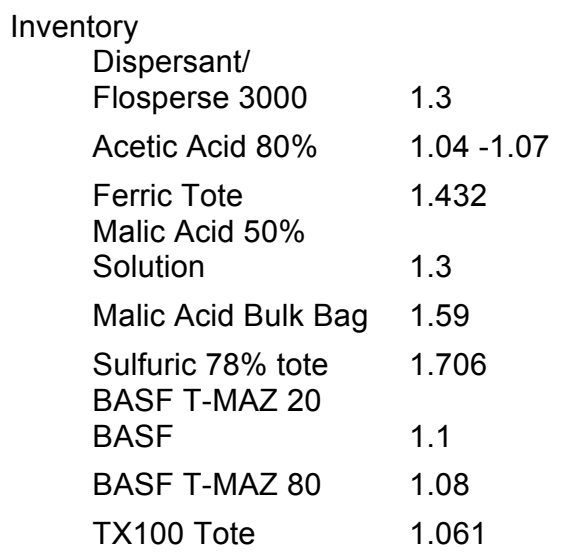

$\begin{array}{rrrrr}5200 & 2600 & 5200 & 2600 & 15600 \\ 23040 & 24101 & 26140 & 14300 & 87581 \\ 2700 & 0 & 2700 & 2700 & 8100 \\ 20302 & 17400 & 14500 & & 52202 \\ & & 3000 & 9300 & 12300 \\ 19698 & 10500 & 21000 & 10500 & 61698 \\ 978 & 1958 & 3912 & 1958 & 8806 \\ 0 & 0 & 1442 & 0 & 1442 \\ 2500 & 5000 & 7500 & 2500 & 17500\end{array}$


VITA

\begin{abstract}
Alan Michael Hanley was born in Tallahassee, Fl on April 27, 1988. After completing high school at Kentucky Country Day School in Louisville, KY, he attended Florida State University in Tallahassee, Fl. In 2008, he left Florida State University to continue his bachelor's degree at the University of Louisville in Louisville, Ky. He received his Bachelor of Chemical Engineering from the university of Louisville on December 13, 2011. After completing his bachelor's degree, he immediately entered the master's program for chemical engineering at the University of Louisville.
\end{abstract}

Permanent Address: 1915 Wrocklage Ave. Unit 208

Louisville, Ky 40205

This thesis was typed by Alan Michael Hanley. 